\title{
Genetically Targeted Binary Labeling of Retinal Neurons
}

\author{
Yongling Zhu, ${ }^{1}$ Jian Xu, ${ }^{1}$ William W. Hauswirth, ${ }^{2}$ and Steven H. DeVries ${ }^{1}$ \\ ${ }^{1}$ Departments of Ophthalmology and Physiology, Northwestern University Feinberg School of Medicine, Chicago, Illinois 60611, and ${ }^{2}$ Department of \\ Ophthalmology, University of Florida, Gainesville, Florida 32610
}

\begin{abstract}
A major stumbling block to understanding neural circuits is the extreme anatomical and functional diversity of interneurons. Subsets of interneurons can be targeted for manipulation using Cre mouse lines, but Cre expression is rarely confined to a single interneuron type. It is essential to have a strategy that further restricts labeling in Cre driver lines. We now describe an approach that combines Cre driver mice, recombinant adeno-associated virus, and rabies virus to produce sparse but binary labeling of select interneurons-frequently only a single cell in a large region. We used this approach to characterize the retinal amacrine and ganglion cell types in five GABAergic Cre mouse (Mus musculus) lines, and identified two new amacrine cell types: an asymmetric medium-field type and a wide-field type. We also labeled several wide-field amacrine cell types that have been previously identified based on morphology but whose connectivity and function had not been systematically studied due to lack of genetic markers. All Cre-expressing amacrine cells labeled with an antibody to GABA. Cre-expressing RGCs lacked GABA labeling and included classically defined as well as recently identified types. In addition to the retina, our technique leads to sparse labeling of neurons in the cortex, lateral geniculate nucleus, and superior colliculus, and can be used to express optogenetic tools such as channelrhodopsin and protein sensors such as GCaMP. The Cre drivers identified in this study provide genetic access to otherwise hard to access cell types for systematic analysis including anatomical characterization, physiological recording, optogenetic and/or chemical manipulation, and circuit mapping.
\end{abstract}

Key words: amacrine cell; Cre recombinase; ganglion cell; rabies virus; retina

\section{Introduction}

Neural circuits are composed of neuron types that have diverse molecular, anatomical, and functional properties. One strategy for linking the function of the entire circuit to the functions of the component neuron units is to target specific cell types and manipulate their activity. Current genetic approaches exploit the molecular diversity of interneurons by linking Cre expression to the expression of a specific gene (Taniguchi et al., 2011; Huang and Zeng, 2013). However, a frequent observation is that Cre expression is rarely confined to a single cell type within a brain region. Strategies for narrowing Cre recombination to either a single neuron or a single neuron type are essential not only for precisely analyzing Cre expression patterns, but also for obtaining unambiguous information about processing in circuits.

Received July 11, 2013; revised April 22, 2014; accepted April 24, 2014.

Author contributions: Y.Z., J.X., and S.H.D. designed research; Y.Z., J.X., and S.H.D. performed research; W.W.H. contributed unpublished reagents/analytic tools; Y.Z. and S.H.D. analyzed data; Y.Z. and S.H.D. wrote the paper.

This work was supported by NIH Grants R01EY018204 (S.H.D.) and T32EY007128 (Y.Z.), and by Research to Prevent Blindness. W.W.H. was supported by NIH Grants R01EY11123 and P30EY021721, and grants from the Macular Vision Research Foundation, Foundation Fighting Blindness, Eldon Family Foundation, Vision for Children, and Research to Prevent Blindness. We thank Drs. Ian Wickersham and Edward Callaway for generously providing cell lines and plasmids for rabies virus production, and Vince Chiodo for providing recombinant adeno-associated virus. We thank Dr. Gregory Schwartz for careful reading and insightful comments on this manuscript.

W.W.H. and the University of Florida have a financial interest in the use of AAV therapies and own equity in a company (AGTC Inc.) that might, in the future, commercialize some aspects of this work. The remaining authors declare no competing financial interests.

Correspondence should be addressed to either Yongling Zhu or Steven H. DeVries, Departments of Ophthalmology and Physiology, Tarry 5-713, Northwestern University Feinberg School of Medicine, Chicago, Illinois 60611; E-mail: yongling-zhu@northwestern.edu or s-devries@northwestern.edu.

DOI:10.1523/JNEUROSCI.2960-13.2014

Copyright $\odot 2014$ the authors $\quad 0270-6474 / 14 / 347845-17 \$ 15.00 / 0$
The retina is an excellent model system in which to study the structure and function of neural circuits including those that give rise to ganglion cell responses. The current view of ganglion cell circuits is that complex computations depend on the input/output synapses of $>30$ types of inhibitory amacrine cells which, through specific connections, modulate signal flow between the axon terminals of $\sim 12$ excitatory bipolar cell types and the dendrites of 15-20 ganglion cell types. The well studied functions of ganglion cells makes their circuits a suitable target for Cre-based approaches, but the sheer number and heterogeneity of modulatory amacrine cell types combined with a paucity of genetic markers for both amacrine and ganglion cells presents challenges for such an approach (MacNeil and Masland, 1998; MacNeil et al., 1999; Diamond and Lukasiewicz, 2012).

Our goals in this study were twofold: first, to identify Cre driver lines in which limited types of amacrine and ganglion cells are targeted; and second, to develop a systematic approach for isolating individual cells and cell types within Cre drivers. Since many amacrine cells are GABAergic, we began by characterizing nine transgenic mouse lines in which Cre expression is controlled by promoters associated with cortical GABAergic neurons (Taniguchi et al., 2011). In almost all the Cre drivers, our characterization was impeded by the expression of Cre in multiple amacrine and ganglion cell types, and thus it became necessary to introduce additional screening steps so as to isolate individual neurons and neuron types. To achieve sparse yet intense labeling, we assembled a viral toolbox containing avian virus envelope protein (EnvA)-pseudotyped rabies virus (Wickersham et al., 2007b) and a Cre-dependent recombinant adeno-associated virus (rAAV) that expresses avian tumor virus receptor A (TVA), the cognate 
receptor for EnvA. This approach permitted genetic targeting and allowed for robust expression of fluorescent markers in a small subset of Cre-expressing neurons. We identified both novel and previously described medium- and wide-field amacrine and ganglion cell types the anatomy of which is normally obscured in populations by extensive process overlap. These Cre driver lines, combined with the ability to refine genetic access, create a basis for a systematic analysis of processing in the inner retina and elsewhere in the CNS.

\section{Materials and Methods}

Mice. All the Cre drivers (for a complete description, see Taniguchi et al., 2011) were purchased from The Jackson Laboratory:

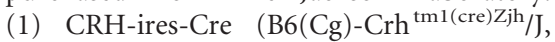
JAX 012704); (2) VIP-ires-Cre (STOCK Vip $^{\mathrm{tm} 1(\mathrm{cre}) Z j \mathrm{~h}} / \mathrm{J}$, JAX 010908); (3) nNOS-

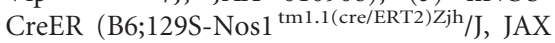
014541); (4) SST(SOM)-ires-Cre (STOCK

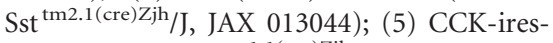

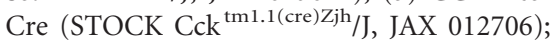
(6) Gad2-ires-Cre (STOCK Gad2 ${ }^{\operatorname{tm} 2(\mathrm{cre}) \mathrm{Zjh} / \mathrm{J}}$ JAX 010802); (7) Lhx6-CreER (B6(Cg)-

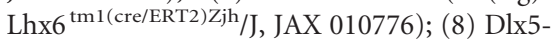
CreER (B6(Cg)-Dlx5 ${ }^{\text {tml(cre/ERT2)Zjh } / J, ~ J A X ~}$ 010705); and (9) CR-ires-Cre (B6(Cg)Calb2 ${ }^{\text {tml(cre)Zjh } / J, ~ J A X ~ 010774) . ~ A i 9 ~ m i c e ~}$ (Madisen et al., 2010; Rosa26-CAG-loxPSTOP-loxP-tdTomato, B6.Cg-Gt(ROSA) 26Sor ${ }^{\text {tm9(CAG-tdTomato)Hze/J, JAX 007909) were }}$ also obtained from The Jackson Laboratory. These lines have been backcrossed to C57BL/6J mice in The Jackson Laboratory, as well as in the authors' laboratory. The Thy1-STOP-YFP mouse line 15 (Buffelli et al., 2003) was a kind gift from Dr. Joshua Sanes (Harvard University, Boston, MA), and was also backcrossed to C57BL/6J mice. Adult mice (5-6 weeks old) of either sex were used for experiments. All animal procedures were performed in accordance with the Guide for the Care and Use of Laboratory Animals as adopted and promulgated by the US National Institutes of Health. All procedures for testing and handling were approved by the Institutional Animal Care and Use Committee of Northwestern University. To activate CreER, tamoxifen $(2 \mathrm{mg} / \mathrm{d}$, for $3 \mathrm{~d}$ ) was injected intraperitoneally at postnatal day 21 . Seven days after the last induction, mice were subjected to tissue analysis or viral injections.

Viral injections. AAV injections were performed on 5- to 6-week-old mice. For cell type-specific labeling of amacrine cells, $1 \mu \mathrm{l}$ of $r A A V 2$ (YF4)-CBA-DIO-TVA $\left(5 \times 10^{12}\right.$ genome copies $/ \mathrm{ml}$, where YF4 indicates four tyrosine to phenylalanine mutations in the capsid) was injected intravitreally. Five weeks later, $1 \mu \mathrm{l}$ of pseudotyped rabies virus EnvA$S A D \Delta G$-GFP $\left[0.5\right.$ to $1 \times 10^{6}$ infectious units (IU) $\left./ \mathrm{ml}\right]$ was injected into the same eye. For cell type-specific labeling of RGCs, $1 \mu$ l of $r A A V 2$ (YF4)CBA-DIO-TVA $\left(1 \times 10^{13}\right.$ genome copies $\left./ \mathrm{ml}\right)$ was injected into the eye. After 5 weeks, $1 \mu \mathrm{l}$ of EnvA-SAD $A$ G-GFP $\left(1 \times 10^{9} \mathrm{IU} / \mathrm{ml}\right)$ was stereotaxically injected into either the LGN (A/P $-2.40 \mathrm{~mm}$ from bregma, $\mathrm{L} / \mathrm{M}$ $2 \mathrm{~mm}, \mathrm{D} / \mathrm{V}-2.75 \mathrm{~mm}$ ) or SC (A/P $-3.70 \mathrm{~mm}$ from bregma, L/M 0.5 $\mathrm{mm}, \mathrm{D} / \mathrm{V}-1.0 \mathrm{~mm})$. The retina was fixed $6 \mathrm{~d}$ after EnvA-SAD $\Delta G-G F P$ injection. To label RGC axonal projections in the brain, $1 \mu \mathrm{l}$ of
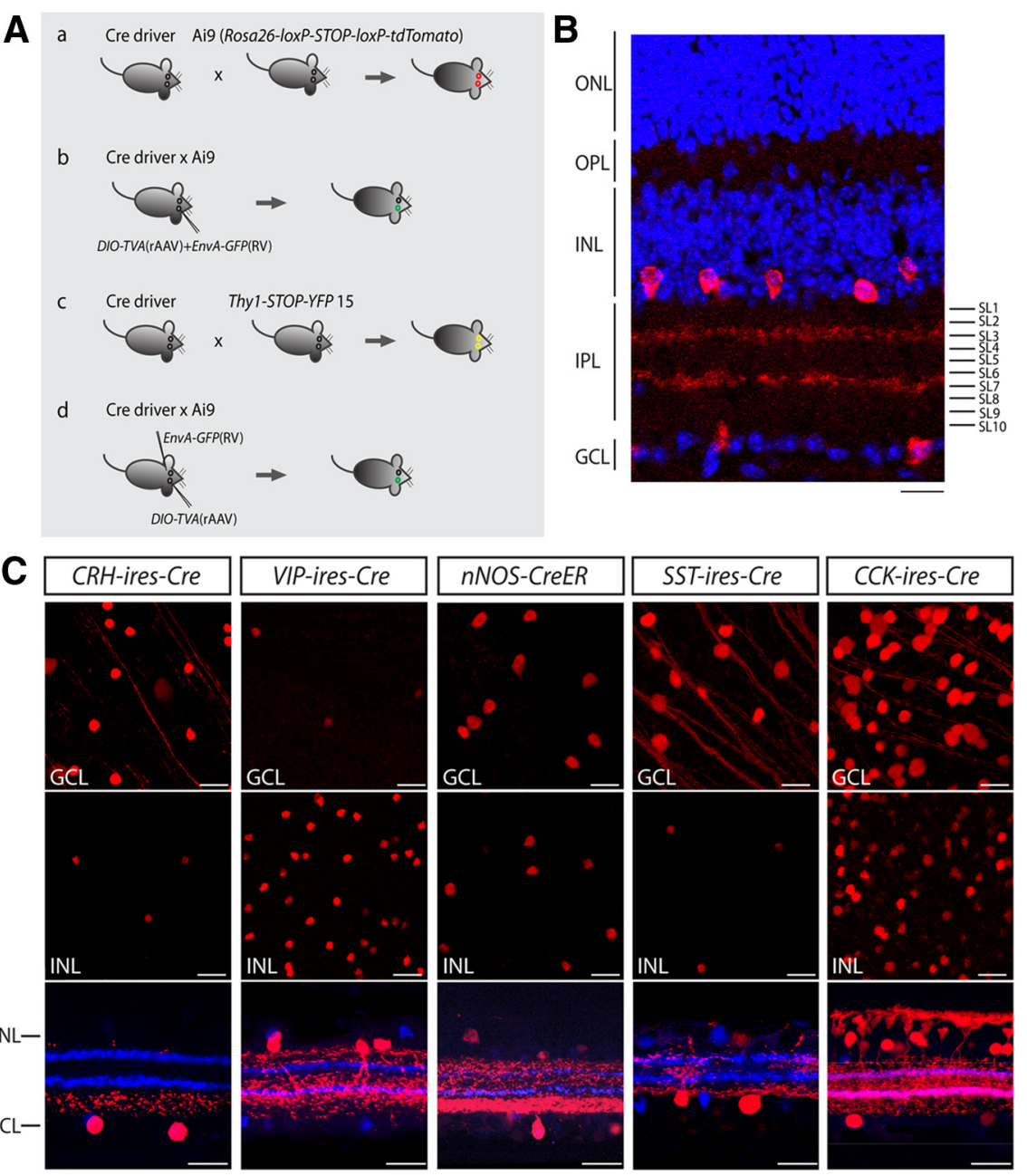

Figure 1. Mouse lines with Cre predominantly expressed in inner retinal neurons. $\boldsymbol{A}$, Screening strategies for cell type-specific expression of Cre in the inner retina. The distribution of Cre-expressing cells was examined by crossing each Cre driver with Ai9 reporter mice $(\boldsymbol{a})$, followed by cell type-specific labeling of amacrine cells with intravitreal injection of a rAAV that codes for a floxed TVA and an EnvA-pseudotyped rabies virus carrying GFP $(\boldsymbol{b})$. Cre expression in ganglion cells was evaluated by crossing each line of the Cre $\times$ Ai9 mice, and EnvA-pseudotyped rabies virus carrying GFP was subsequently applied to ganglion cell axonal terminals in a retino-recipient area such as the $L G N$ or $S C(\boldsymbol{d})$. $\boldsymbol{B}$, Organization of the retina and definition of IPL stratification. A vertical section 列 as $0-100 \%$ from the border of the INL to the border of the GCL. The positions of ON and OFF-ChAT bands were estimated at $60 \%$ and $27 \%$ of the IPL, respectively. The IPL can be further divided into 10 equal strata or sublaminae (SL1-SL10) in which the ChAT cells in the CRH-ires-Cre, VIP-ires-Cre, nNOS-CreER, SST-ires-Cre, and CCK-ires-Cre retinas. Each driver was crossed with Ai9 mice sections with ChAT (blue; bottom). Scale bar $25 \mu \mathrm{m}$.

$r A A V 2(Y F 4)-C B A-D I O-G F P\left(1 \times 10^{13}\right.$ genome copies/ml) was injected into the eye. Five weeks later, the same eye was injected with $5 \mu$ l of cholera toxin $\beta$ conjugated to Alexa Fluor 594 (Ctb-594: 1\% in saline; Invitrogen). The animal was perfused transcardially with $4 \%$ paraformaldehyde after $24 \mathrm{~h}$, and the brain and the retinas were removed for further fixation. For cell type-specific labeling in brain, $0.3 \mu$ of $r A A V 2(Y F 4)-C B A-D I O-T V A\left(5 \times 10^{12}\right.$ genome copies $\left./ \mathrm{ml}\right)$ was stereotaxically injected into each region (primary motor cortex area $\mathrm{M} 1: \mathrm{A} / \mathrm{P}$ $1.2 \mathrm{~mm}$ from bregma, L/M $0.6 \mathrm{~mm}, \mathrm{D} / \mathrm{V} 0.4 \mathrm{~mm}$; primary somatosensory cortex area S1: A/P - $1.1 \mathrm{~mm}$ from bregma, L/M $3.3 \mathrm{~mm}$, D/V 0.4 $\mathrm{mm}$; and primary visual cortex area $\mathrm{V} 1: \mathrm{A} / \mathrm{P}-3.4 \mathrm{~mm}$ from bregma, $\mathrm{L} / \mathrm{M}$ $2.5 \mathrm{~mm}, \mathrm{D} / \mathrm{V} 0.3 \mathrm{~mm})$. After 3 weeks, $0.3 \mu \mathrm{l}$ of EnvA-SAD $\Delta G-G F P(1 \times$ $10^{5}$ to $1 \times 10^{7} \mathrm{IU} / \mathrm{ml}$ ) was injected into the same site. The brain was removed $7 \mathrm{~d}$ later for examination. For calcium imaging and electrophysiology, $1 \mu$ l of $r A A V 2(Y F 4)-C B A-D I O-T V A\left(5 \times 10^{12}\right.$ genome copies/ 


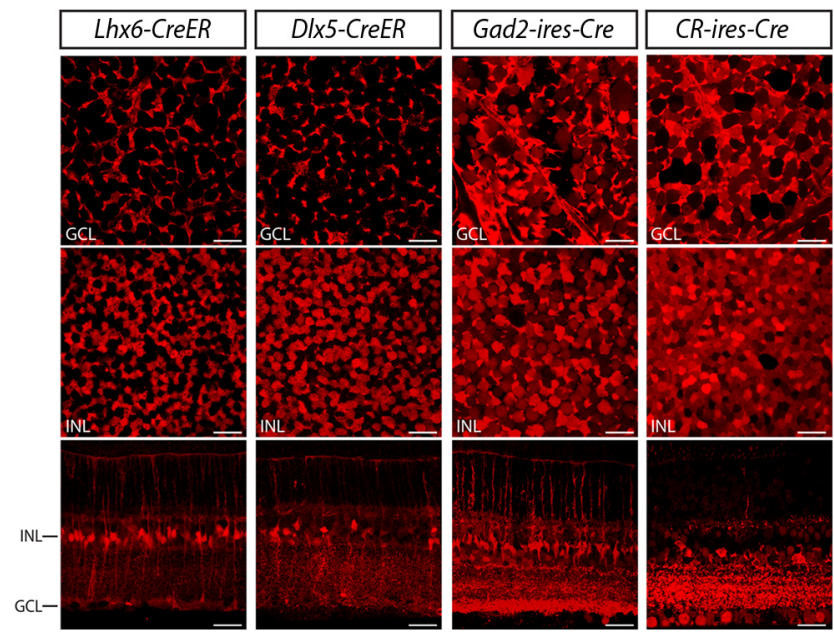

Figure 2. Distribution of Cre-expressing cells in the Lhx6-CreER, Dlx5-CreER, Gad2-ires-Cre, and $C R$-ires-Cre retinas. Each driver was crossed with Ai9 mice. TdTomato-labeled cells were located in the GCL (top) and the INL (middle panels) in both flat-mount (top and middle) and vertical sections (bottom). CreER in the Lhx6-CreER and D/x5-CreER drivers was activated with tamoxifen injections. Scale bar, $25 \mu \mathrm{m}$.

$\mathrm{ml})$ was injected into the eye. Five weeks later, $1 \mu \mathrm{l}$ of EnvA-SAD $\Delta G$ GCaMP3 $\left(1 \times 10^{8} \mathrm{IU} / \mathrm{ml}\right)$ or EnvA-SAD $\Delta G$-ChR2-venus $\left(2 \times 10^{7} \mathrm{IU} /\right.$ $\mathrm{ml}$ ) was injected into the same eye. The retina was removed $6-7 \mathrm{~d}$ later for recording. $r A A V 2$ (YF4)-CBA-DIO-TVA was manufactured by the Retina Gene Therapy Group at the University of Florida and S. H. DeVries' (S.H.D.'s) laboratory at Northwestern University. rAAV2(YF4)CBA-DIO-GFP and EnvA-SAD $\Delta G$-GFP were produced in S.H.D.'s laboratory at Northwestern University.

Immunohistochemistry and imaging. For immunohistochemistry in the retina, mice were killed, and the eyes were removed and fixed with $4 \%$ paraformaldehyde $(1.5 \mathrm{~h})$ and then dissected from the eyecup. After washing six times each for 30 min with a modified phosphate buffer (PB) containing $0.5 \%$ Triton $\mathrm{X}-100$ and $0.1 \% \mathrm{NaN}_{3}, \mathrm{pH} 7.4$, retinas were blocked for $2 \mathrm{~d}$ in modified PB containing 3\% donkey serum. Retinas were then incubated with primary antibody diluted in modified $\mathrm{PB}$ plus $3 \%$ donkey serum for 5-7 d. After six washes for $30 \mathrm{~min}$ each, the retinas were incubated in donkey secondary antibody for $2 \mathrm{~d}$ at $4^{\circ} \mathrm{C}$. For brain labeling and projection studies, mice were perfused transcardially with $4 \%$ paraformaldehyde and postfixed for $3-5 \mathrm{~d}$ at $4^{\circ} \mathrm{C}$. After washing with phosphate buffered saline, the brains were sectioned at $80 \mu \mathrm{m}$ with a vibratome. Immunohistochemistry proceeded as for the retina.

The primary antibodies used were as follows: rabbit anti-GFP (1:2000, Invitrogen), chicken anti-GFP (1:1000, Abcam), rabbit anti-RFP (1: 1000, Rockland), goat anti-choline acetyltransferase (1:500, Millipore), rabbit anti-GABA (1:2000, Sigma-Aldrich), rabbit anti-VIP (1:1000, ImmunoStar), rabbit anti-nNos (1:1000, Invitrogen), and rat anti-SST (1: 10 , Millipore). Secondary antibodies were conjugated to Alexa Fluor 488 (Invitrogen), Cy3 (Jackson ImmunoResearch), or Cy5 (Jackson ImmunoResearch). All secondary antibodies were used at a dilution of 1:200.

Imaging and morphological analysis. Retina spanning images of widefield amacrine cells were captured with a Nikon A1R confocal microscope using a $10 \times$ objective and the image stitching function. Somata and nearby processes were additionally imaged with a Zeiss LSM-510 Meta confocal microscope using a $25 \times$ objective and $1.45 \mu \mathrm{m} Z$-stack steps. The same LSM-510 confocal settings were used to capture the structure of medium-field amacrine cells and RGCs. For wide-field amacrine cells, complete morphologies were traced in Neurolucida using Neuron Tracing Software (MBF Bioscience). The classification was based on four parameters: soma size, dendritic field size in the ON and OFF sublaminae, symmetry of the dendritic field, and stratification of arbors. To measure the size of the dendritic field, a convex polygon was drawn connecting the outermost tips of the dendrites, and the area within this contour was measured. The diameter of the dendritic field was calculated from the measured area by assuming the dendritic field is circular. Soma diameter was calculated in the same way. The symmetry index was calculated as the distance of the soma to the center of the polygonal dendritic field divided by the diameter of the dendritic field. Data are presented as mean $\pm \mathrm{SD}$.

The level of stratification of amacrine cells and RGCs was measured with LSM Image software (Zeiss). A rectangle representing the region of interest (ROI; $\sim 195 \mu \mathrm{m} \times 30 \mu \mathrm{m}$ ) was placed near the center of a dendritic field. The image data within the ROI at each level of the $z$-stack was projected onto the $x$-axis. The stratification levels of amacrine or ganglion cell dendrites were determined from the upper and lower boundaries of GFP-labeled arbors relative to the choline acetyltransferase (ChAT)-positive bands in XZ plane. Later, the same procedure was repeated on the middle and distal parts of the dendritic field or "axon-like" arbors to verify the consistency of stratification in different parts of the retinal coverage area. Data are presented as mean \pm SD.

Gaussian fitting. The measured soma diameters were grouped and fitted with one or more Gaussian distributions in Origin (OriginLab). Goodness of fit was evaluated with a $\chi^{2}$ test and iteratively optimized, when necessary, by adding Gaussian curves to the fit.

Two-photon calcium imaging. Mice were dark-adapted for at least $2 \mathrm{~h}$. Eyes were enucleated under dim red illumination, and the retinas were dissected from the eyecup under infrared illumination and mounted vitreal side up in the recording chamber. Tissue was continuously superfused with oxygenated $\left(95 \% \mathrm{O}_{2}-5 \% \mathrm{CO}_{2}\right)$ Ames medium at room temperature and imaged with a two-photon microscope system (Thorlabs) equipped with a Mai Tai DeepSee ultrafast laser (Spectra-Physics) tuned to $930 \mathrm{~nm}$. Label cells were visualized with a $20 \times$ objective (XLUMPLFLN, 1.0 numerical aperture, Olympus). Visual stimuli were generated with a custom-made LED array (Saszik and DeVries, 2012) projected onto the retina through the microscope condenser. The stimulus intensity at $565 \mathrm{~nm}$ was $5 \times$ $10^{-6} \mathrm{~W}-\mathrm{cm}^{-2}\left(1 \times 10^{13}\right.$ photons- $\left.\mathrm{cm}^{-2} \cdot \mathrm{s}^{-1}\right)$. Stimulus duration was $200 \mathrm{~ms}$. Images $(416 \times 416$ pixels $)$ were acquired at 8 frames per second, and pixel size was $0.65 \times 0.65 \mu \mathrm{m}$ on the retina. Data were analyzed with SimplePCI (Compix Inc.).

Electrophysiology. Light-adapted retinas were removed from the eyecup and mounted vitreal side up in a recording chamber on a Zeiss Axioskop-2 microscope. The retina was held in place with a tissue "harp" (Warner Instruments). Tissue was continuously superfused with a standard external solution that contained the following (in $\mathrm{mm}$ ): $115 \mathrm{NaCl}$, $3.1 \mathrm{KCl}, 2.48 \mathrm{MgSO}_{4}, 6$ glucose, 1 sodium succinate, 1 sodium malate, 1 sodium lactate, 1 sodium pyruvate, $2 \mathrm{CaCl}_{2}$, and $25 \mathrm{NaHCO}_{3}$, maintained at a $\mathrm{pH}$ of 7.4 by bubbling with $5 \% \mathrm{CO}_{2}-95 \% \mathrm{O}_{2}$. Recordings were made at room temperature. Whole-cell recordings were obtained with an Axopatch 200B amplifier (Molecular Devices). Borosilicate glass electrodes pulled to $8-12 \mathrm{M} \Omega$ were filled with the following (in $\mathrm{mM}$ ): $80 \mathrm{KCl}$, $30 \mathrm{CsCl}, 2 \mathrm{MgSO}_{4}, 10 \mathrm{HEPES}, 10 \mathrm{Cs}$-EGTA, 5 ATP, $0.5 \mathrm{GTP}$, pH 7.4. Sulforhodamine 101 (0.1 mm; Invitrogen) and $10 \mathrm{~mm}$ Neurobiotin (Vector Laboratories) were added to visualize the recorded cells. ChR2venus-expressing ganglion and amacrine cells were targeted for recording using epifluorescence (Chroma Technology EGFP filter set \#41018). To activate ChR2 (channelrhodopsin) during whole-cell recording, light from an X-Cite 120 PC metal halide source (EXFO) was directed through the epifluorescence port and a $470 \pm 20 \mathrm{~nm}$ bandpass filter (Chroma Technology, HQ470/40x). The stimulus intensity at the retina was $3.05 \mathrm{~W}-\mathrm{cm}^{-2}$ (equivalent to $7 \times 10^{18}$ photons- $\mathrm{cm}^{-2} \cdot \mathrm{s}^{-1}$ ). Stimulus duration was controlled by the built-in X-Cite shutter. Currents were recorded both in standard solution and standard solution with added synaptic blockers [50 $\mu \mathrm{M}$ concentration each of picrotoxin, strychnine, CNQX (Tocris Bioscience), and APV (Tocris Bioscience)]. Cell voltage was maintained at $-70 \mathrm{mV}$. After recording, the retina was fixed and processed for immunohistochemistry.

\section{Results}

\section{Screening strategy}

We provide a summary of our screening and binary labeling strategy (Fig. $1 A$ ) with a more detailed description to follow. The initial stage of screening was to acquire an overview of Cre ex- 
A
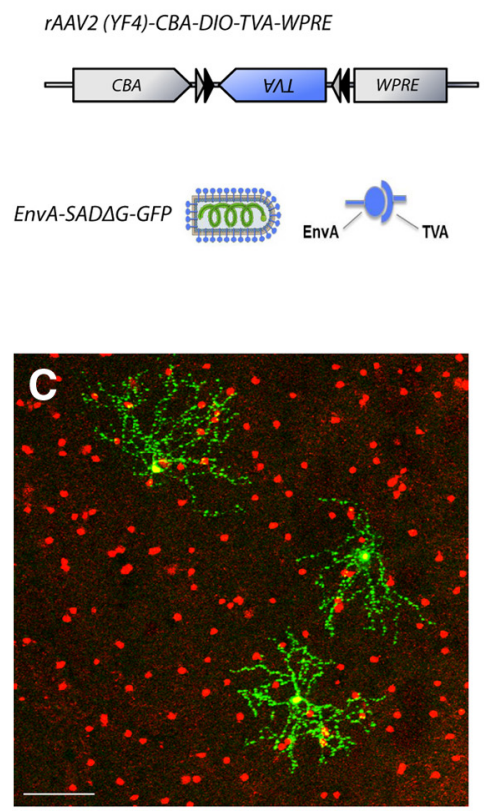

B

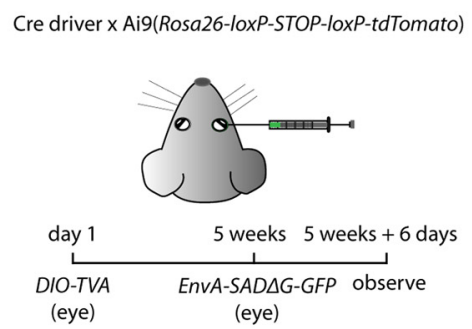

E

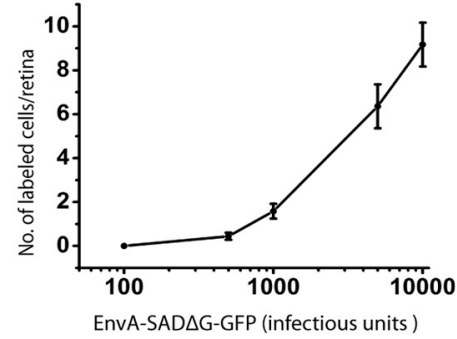

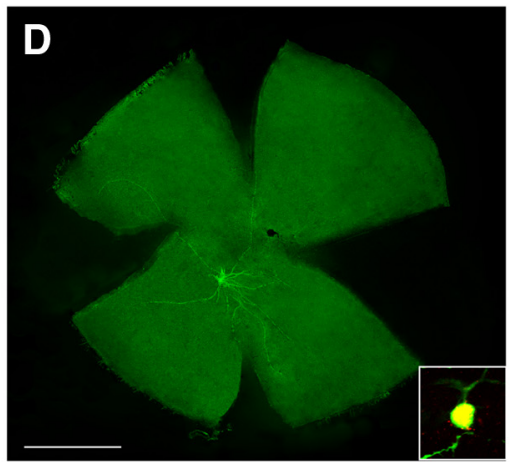

Figure 3. Labeling strategy for single-cell analysis. $\boldsymbol{A}$, rAAV and pseudotyped rabies virus used for intravitreal injections. $\boldsymbol{B}$, Scheme of experimental design. $\boldsymbol{C}$, Three GFP medium-field amacrine cells were discretely labeled in a retina. The image shows an overlay of GFP (green) and tdTomato labeling (red). Note the colocalization of GFP and tdTomato in the somata. Scale bar $100 \mu m$. $\boldsymbol{D}$, A single wide-field amacrine cell was labeled in a different retina. The image is shown as GFP labeling alone. Inset, Coexpression of GFP (green) and tdTomato (red) in the soma. Scale bar, $1 \mathrm{~mm}$. Retinas in $\boldsymbol{C}$ and $\boldsymbol{D}$ are from CRH-ires-Cre $\times$ Ai9 mice. $\boldsymbol{E}$, Dose-dependent labeling of Cre-expressing cells in the CRH-ires-Cre driver by the rAAV/EnvA rabies virus combination. Because labeling density is more sensitive to the dose of EnvA rabies virus than to that of rAAV, we fixed the amount of rAAV while adjusting the dose of EnvA rabies virus and measured the number of labeled cells/retina. A total of $5 \times 10^{9}$ genome copies of $r A A V 2$ (YF4)-CBA-DIO-TVA were injected into an eye followed by a variable dose of EnvA-SAD $\triangle G$-GFP (plotted on a logarithmic scale). Single-cell labeling occurred at 500 ( $0.44 \pm 0.16$ labeled cells/retina) -1000 ( $1.58 \pm 0.34$ labeled cells $/$ retina) IU of EnvA-SAD $\Delta G$-GFP. Data are presented as mean \pm SEM ( $n=13$ retinas for 100 IU; $n=16$ retinas for $500 \mathrm{IU} ; n=12$ retinas for $1000 \mathrm{IU} ; n=14$ retinas for $5000 \mathrm{IU}$, and $n=6$ retinas for $10,000 \mathrm{IU})$.

pression in each driver line by crossing the line with Ai9 reporter mice (Rosa26-loxP-STOP-loxP-tdTomato; Fig. 1Aa). We then sparsely labeled the Cre-expressing amacrine cells in each line by injecting eyes with a combination of a rAAV that codes for a floxed form of TVA, a receptor for the avian viral coat protein EnvA, and an EnvA-pseudotyped rabies virus (Fig. 1Ab). Cre expression patterns in ganglion cells were evaluated by crossing each driver line with Thy1-STOP-YFP reporter mice (line 15; Fig. $1 A c)$. To individually label ganglion cells, TVA-encoding rAAV was introduced into the eye and EnvA-pseudotyped rabies virus was subsequently applied to ganglion cell axonal terminals in a retino-recipient area (LGN or SC) and retrogradely transported back to the soma and dendrites (Fig. 1Ad).

\section{Overview of labeled cells in the inner retina}

We started by screening the labeling pattern of Cre-expressing cells in nine GABAergic Cre driver lines crossed with Ai9 reporter mice. Among the nine lines, two, Lhx6-CreER and Dlx5-CreER, expressed Cre predominantly in Müller glial cells and were excluded from our sample (Fig. 2). In another two lines, Gad2-iresCre and CR-CreER, the broad expression of Cre in numerous types of amacrine and ganglion cells (and in the case of Gad2-iresCre, also Müller cells) made further characterization difficult, and these lines were also excluded from further analysis. In the remaining five lines, including $C R H$-ires-Cre, VIP-ires-Cre, $n N O S$-CreER, SST-ires-Cre, and CCK-ires-Cre, Cre activity was primarily detected in amacrine and ganglion cells (Fig. 1C). Consequently, we focused on these five lines, and present an overview of labeling below.
Each of the five lines contained labeled cells in both the inner nuclear layer (INL) and ganglion cell layer (GCL). Cells in the INL that project into the inner plexiform layer (IPL) include bipolar and amacrine cells, whereas cells in the GCL that stratify in the IPL are either ganglion or displaced amacrine cells. We grouped cells into classes based on the position of their somata in the INL or GCL, as well as on the morphology of their axons and dendrites. Bipolar and amacrine cells in the INL were distinguished by the presence (bipolar cells) or absence (amacrine cells) of stout dendrites extending to the outer plexiform layer. Ganglion and displaced amacrine cells were distinguished by the presence (ganglion cells) or absence (displaced amacrine cells) of axons that course along the vitreal surface of the retina. For weakly labeled cells whose axons were difficult to visualize, we made a preliminary identification based on the size and shape of their somata. For example, displaced amacrine cells have small rounded somata $(4-15 \mu \mathrm{m}$ in diameter) compared with most ganglion cells (9-30 $\mu \mathrm{m}$ in diameter; Kolb et al., 1981; Perry, 1981; Hayes, 1984). Specific neuron types within classes were distinguished by their level of neurite (amacrine cells) or dendrite (RCGs) stratification in 10 IPL layers (Siegert et al., 2009;(Fig. $1 B)$, and by the diameters of their dendritic trees.

In the $\mathrm{CRH}$-ires-Cre driver line, $92 \%$ of the Cre-positive cells were located in the GCL, and $8 \%$ were in the INL (Fig. $1 C, n=$ 572 cells from 8 retinas). Most of the labeled cells in the GCL had small, brightly labeled somata and were presumably displaced amacrine cells. The remaining cells in the GCL layer had large, weakly labeled somata and were sparsely distributed. These latter cells were RGCs insofar as they had axons. 
Table 1. Titer and timing of viral injections

\begin{tabular}{|c|c|c|c|c|c|c|}
\hline Cre driver & Cell type & $\begin{array}{l}\text { Titer of rAAV } \\
\text { (genome copies) }\end{array}$ & rAAV injection site & $\begin{array}{l}\text { Titer of } \mathrm{RV}^{b} \\
\text { (infectious units) }\end{array}$ & RV injection site & $\begin{array}{l}\text { Timing of RV injection } \\
\text { (post rAAV injection) }\end{array}$ \\
\hline CRH & CRH-1 AC & $5 \times 10^{9}$ & Eye & $500-1000$ & Eye & 5 weeks \\
\hline CRH & CRH-2AC & & & & & \\
\hline VIP & VIP-1 AC & & & & & \\
\hline nNOS & nNOS-1 AC & & & & & \\
\hline nNOS & $\mathrm{nNOS}-2 \mathrm{AC}$ & & & & & \\
\hline SST & SST-1 AC & & & & & \\
\hline CCK & SAC & & & & & \\
\hline CCK & A17 & & & & & \\
\hline CCK & CCK-1 RGC & $1 \times 10^{10}$ & Eye & $10^{6}$ & LGN or SC & 5 weeks \\
\hline CCK & CCK-2 RGC & & & & & \\
\hline CCK & CCK-3 RGC & & & & & \\
\hline CCK & M1 cells & $1.5 \times 10^{9}$ & M1 & 300 & M1 & 3 weeks \\
\hline CCK & S1 cells & & S1 & & S1 & \\
\hline CCK & V1 cells & & V1 & & V1 & \\
\hline CCK & SC cells & & SC & & SC & \\
\hline SST & M1 cells & $1.5 \times 10^{9}$ & M1 & 30 & M1 & 3 weeks \\
\hline SST & S1 cells & & S1 & & S1 & \\
\hline SST & V1 cells & & V1 & & V1 & \\
\hline SST & SC cells & & SC & & SC & \\
\hline CCK & LGN cells & $1.5 \times 10^{9}$ & LGN & 3000 & LGN & 3 weeks \\
\hline SST & LGN cells & $1.5 \times 10^{9}$ & LGN & 3000 & LGN & 3 weeks \\
\hline
\end{tabular}

AC, Amacrine cell.

arAAV2 (YF4)-CBA-DI0- TVA.

${ }^{b}$ Rabies virus EnvA-SADSG-GFP.

In the VIP-ires-Cre driver line, $91 \%$ of the Cre-positive cells were located in the INL, and only $9 \%$ of the cells were observed in the GCL (Fig. 1C, $n=833$ cells from 8 retinas). VIP-ires-Cre cells had small cell bodies, and vertical sections suggested they were all amacrine cells.

In the $n N O S$-CreER driver line, the Cre-positive cells were almost equally distributed between the INL (46\%) and GCL (54\%; Fig. 1C, $n=725$ cells from 8 retinas). Vertical sections indicated that most of the cells in the INL were amacrine cells, along with a small fraction of bipolar cells. The cell bodies in the GCL were $\sim 14 \mu \mathrm{m}$ in diameter, and no ganglion cell axons were visible. nNOS-Cre cells in the GCL were most likely displaced amacrine cells.

In the SST-ires-Cre driver line, most (75\%) Cre-positive cells were located in the GCL with the remainder in the INL (Fig. $1 C$, $n=663$ cells from 8 retinas). In addition to large ganglion cell bodies, a group of smaller, round cell bodies was observed in the GCL, suggesting that displaced amacrine cells were also present in this line. Vertical sections revealed that the cells in the INL were amacrine cells.

In the CCK-ires-Cre line, Cre expression was observed in bipolar, amacrine, ganglion, and Müller cells (Fig. $1 C, n=987$ cells from 6 retinas). Bipolar cells made up more than half of the labeled cells in the INL, with the rest being amacrine and a small number of Müller cells. The GCL contained both labeled ganglion and amacrine cells.

Thus, each line has multiple labeled types in the INL and GCL. Cross-sectional views, in particular, show that the processes of neighboring cells in both the same and different types extensively overlap. This overlap makes it hard to define the morphology of individual cells of a given type.

\section{Cre-expressing amacrine cell types}

Amacrine cells can be categorized into two subclasses based on the neurotransmitter that they contain: GABAergic and glycinergic. Glycinergic interneurons are usually compact or "narrowfield" (arbor $<125 \mu \mathrm{m}$ in diameter), and are relatively easy to delineate anatomically. GABAergic amacrine cells are often "medium-field" (arbor 125-400 $\mu \mathrm{m}$ in diameter) or "wide-field" (arbor $>400 \mu \mathrm{m}$ in diameter; MacNeil and Masland, 1998), and are characterized by extreme morphological diversity and, as a population, by extensive process overlap. Because of process overlap among wide-field amacrine cells and between wide-field amacrine and ganglion cells, it was difficult to determine how many amacrine cell types were labeled and to characterize their anatomy in the simple Ai9 crosses. Consequently, we sought a labeling strategy with two characteristics. First, many wide-field amacrine cells have neurites that span more than half of the retina; therefore, extremely sparse labeling, ideally one cell per retina, would be preferred to avoid process overlap. Second, to illuminate the thin neurites that often run for several millimeters within the retina, a strong and uniform labeling technique is required.

To meet these requirements, we used a modified rabies virus (EnvA-SAD $\Delta G-G F P)$ to deliver a fluorescent marker to Creexpressing cells. EnvA-SAD $\Delta G-G F P$ was developed for use in monosynaptic-transsynaptic tracing from genetically identified cell types, and contains two key modifications relative to the wild- 
type rabies virus. First, the rabies virus envelope glycoprotein $(G)$ responsible for transsynaptic spread is replaced with GFP to mark the host cell and to eliminate endogenous transsynaptic spread (Wickersham et al., 2007a). Second, the virus is pseudotyped with EnvA. EnvA-coated virus lacks the ability to infect mammalian host cells unless those cells have been engineered to express the avian receptor TVA (Wickersham et al., 2007b). Because neither of the modifications interferes with the replication process of the rabies virus within the infected cell, GFP production is extremely high, and labeling is bright.

In this study, we restricted EnvA-SAD $\Delta G^{-}$ GFP expression to Cre-expressing cells without initiating transsynaptic spread. We generated a tyrosine capsid mutant rAAV serotype 2 (Zhong et al., 2008; Petrs-Silva et al., 2011) that carried Cre-dependent TVA (rAAV2(YF4)-CBA-DIO-TVA). This virus was delivered to double transgenic Cre driver $\times$ Ai9 mice via intravitreal injection (Fig. $3 A, B$ ). Five weeks after rAAV injection, EnvA-SAD $\triangle G-G F P$ was injected into the same eye and the retina was examined $6 \mathrm{~d}$ later. The targeted expression of GFP in Cre-expressing cells was verified by coexpression of GFP and tdTomato in the soma. We controlled the density of labeled cells by adjusting the dose of rAAV and EnvA$S A D \Delta G-G F P$ (Fig. $3 E$, Table 1). This strategy allowed us to label very few cells in each retina (Fig. $3 C$ ), and single-cell labeling could be routinely achieved (Fig. 3D). Meanwhile, GFP expression was extremely strong in the labeled cells, clearly revealing morphology.

The CRH-ires-Cre driver targets two types of amacrine cells Sparse labeling in the CRH-ires-Cre line revealed two morphological types of displaced amacrine cells. The first type (named CRH-1) was a medium-field cell with a small soma (11.3 \pm 2.3 $\mu \mathrm{m}$ in diameter, $n=18$ cells from 11 retinas) and an intermediate-sized dendritic tree ( $224 \pm 36 \mu \mathrm{m}$ in diameter). A hallmark of these cells was the presence of spiny dendrites distributed asymmetrically around the soma (Figs. 3C, 4A). The soma gave rise to 4-6 primary arbors that further branched and stratified within a narrow band near the GCL $[83 \pm 7 \%$ of the IPL, sublamina 8 (SL8)-SL9; Fig. 4B, Table 2]. CRH-1 amacrine cells use GABA as a neurotransmitter (Fig. $4 I$ ), and do not appear in previous classifications of amacrine cells (MacNeil and Masland, 1998; MacNeil et al., 1999; Badea and Nathans, 2004).

The second labeled cell type (CRH-2) was a bistratified widefield amacrine cell (Fig. 4C,D). CRH-2 cells had a complex, "disorganized" morphology that is characteristic of many types of wide-field amacrine cells. A displaced soma (13.9 $\pm 2.0 \mu \mathrm{m}$ diameter, $n=10$ cells from 10 retinas) gave rise to $3-6$ thick primary dendrites (Fig. 4E). Primary dendrites tapered and gave rise to multiple thinner branches that ramified distally, close to the INL ( $9 \pm 5 \%$ of the IPL, SL1-SL2), or near the GCL ( $84 \pm 6 \%$ of the IPL, SL8-SL9; Fig. 4F, Table 2). Thick primary dendrites also gave rise to one or two very thin axon-like processes that branched further to produce 3-5 processes, all near the bottom of the IPL ( $83 \pm 5 \%$ of the IPL for the proximal segments, and $84 \pm$ $3 \%$ for the distal segments; Fig. 4G,H, Table 2). These processes crossed extensively near the soma before extending to the entire retina. CRH-2 amacrine cells were GABAergic (Fig. 4J), and are morphologically similar to the previously described A1 widefield amacrine cell (Famiglietti, 1992; Stafford and Dacey, 1997; Badea and Nathans, 2004).

\section{A type of wide-field amacrine cell is targeted in the VIP-ires- \\ Cre driver}

The VIP-ires-Cre driver line demonstrated a relatively simple Cre expression pattern. All the GFP-labeled amacrine cells appeared to belong to a single type (VIP-1; Fig. 5A). Most (91\%) VIP-1 somata were located in the INL and had a diameter of $11.0 \pm 1.1$ $\mu \mathrm{m}$. Primary dendrites emerged from the soma and descended to the bottom of sublamina $b$ where they extensively ramified ( $67 \pm$ $11 \%$ of the IPL, SL6-SL8, $n=22$ cells from 7 retinas; Fig. 5B). A few processes emerged from the soma and ramified near the INL ( $14 \pm 8 \%$ of the IPL, SL1-SL3). The ON and OFF dendritic fields were $294 \pm 90$ and $280 \pm 83 \mu \mathrm{m}$ in diameter, respectively. Many of the cells had a relatively long process that extended $\sim 400 \mu \mathrm{m}$ from the soma (Fig. 5D). These cells used GABA as neurotransmitter (Fig. 5C) and resemble previously described "waterfall" cells in mouse (Badea and Nathans, 2004).

\section{The $n N O S-C r e E R$ driver targets two types of wide-field amacrine cells}

The $n N O S$-CreER driver specifically marked two types of widefield amacrine cells. The first type (nNOS-1) was morphologically similar and probably identical to the CRH-2 amacrine cell 
Table 2. Summary of amacrine cell types in Cre driver lines

\begin{tabular}{|c|c|c|c|c|c|c|}
\hline Cre driver & Cell type & Soma location & Soma diameter ( $\mu \mathrm{m})$ & Dendritic diameter ( $\mu \mathrm{m})$ & $\begin{array}{l}\text { Dendritic stratification } \\
(\% \text { in } I P L)\end{array}$ & $\begin{array}{l}\text { Axon-like process } \\
\text { stratification (\% in IPL) }\end{array}$ \\
\hline \multirow[t]{2}{*}{ CRH } & \multirow{2}{*}{ (RH- $1 \mathrm{AC}$ ( $n=18$ from 11 retinas) } & \multirow[t]{2}{*}{$\mathrm{GCL}$} & \multirow{2}{*}{$11.3 \pm 2.3$} & \multirow[t]{2}{*}{$224 \pm 36$} & $83 \pm 7$ (on) & NA \\
\hline & & & & & $84 \pm 6$ (on) & $83 \pm 5$ (proximal) \\
\hline \multirow[t]{2}{*}{$\mathrm{CRH}$} & \multirow[t]{2}{*}{ (RH-2 AC ( $n=10$ from 10 retinas) } & \multirow[t]{2}{*}{$\mathrm{GCL}$} & \multirow[t]{2}{*}{$13.9 \pm 2.0$} & $311 \pm 51$ & $9 \pm 5$ (off) & \multirow[t]{2}{*}{$84 \pm 3$ (distal) } \\
\hline & & & & $294 \pm 90$ (on) & $67 \pm 11$ (on) & \\
\hline \multirow[t]{2}{*}{ VIP } & \multirow[t]{2}{*}{ VIP- $1 \mathrm{AC}^{a}$ ( $n=22$ from 7 retinas) } & \multirow[t]{2}{*}{ INL } & \multirow[t]{2}{*}{$11.0 \pm 1.1$} & \multirow[t]{2}{*}{$280 \pm 83$ (off) } & $14 \pm 8$ (off) & NA \\
\hline & & & & & $84 \pm 5$ (on) & $84 \pm 7$ (proximal) \\
\hline nNOS & $\mathrm{nNOS}-1 \mathrm{AC}^{a}$ ( $n=10$ from 10 retinas) & $\mathrm{GCL}$ & $13.9 \pm 1.3$ & $266 \pm 50$ & $8 \pm 6$ (off) & $83 \pm 4$ (distal) \\
\hline \multirow[t]{2}{*}{ nNOS } & \multirow[t]{2}{*}{$\mathrm{nNOS}-2 \mathrm{AC}^{a}(n=8$ from 3 retinas $)$} & \multirow[t]{2}{*}{$\operatorname{INL}(75 \%)$ GCL (25\%) } & \multirow[t]{2}{*}{$12.0 \pm 2.0$} & \multirow[t]{2}{*}{$2620 \pm 570$} & \multirow[t]{2}{*}{$47 \pm 3$} & NA \\
\hline & & & & & & $86 \pm 9$ (proximal) \\
\hline SST & SST- $1 \mathrm{AC}^{a}$ ( $n=17$ from 17 retinas) & $\mathrm{GCL}$ & $15.6 \pm 2.0$ & $337 \pm 64$ & $88 \pm 10$ (on) & $8 \pm 3$ (distal) \\
\hline CCK & $\mathrm{SAC}(n=9$ from 6 retinas $)$ & GCL INL & $13.0 \pm 1.9$ & $266 \pm 31$ & $60 \pm 2$ (on) & NA \\
\hline CCK & A17 ( $n=5$ from 5 retinas) & INL & $10.9 \pm 1.3$ & $848 \pm 45$ & $90 \pm 2$ (on) & NA \\
\hline
\end{tabular}

Data are presented as mean \pm SD. AC, Amacrine cell; NA, not applicable.

${ }^{a}$ Cells express the protein corresponding to the promoter.
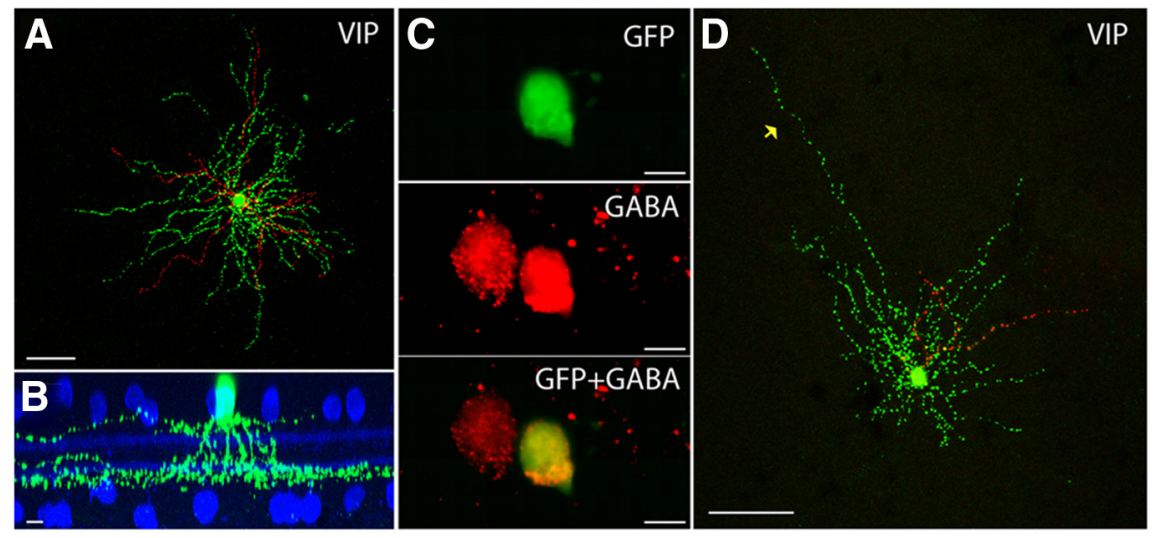

Figure 5. The VIP-ires-Cre driver targets one amacrine cell type. A, A VIP-1 wide-field amacrine cell is shown in flat-mount view with soma and $\mathrm{ON}$ arbors labeled in green, and OFF arbors pseudocolored in red. Scale bar, $50 \mu \mathrm{m}$. B, Side view with ChAT (blue) of the cell in $\boldsymbol{A}$. Scale bar, $10 \mu \mathrm{m}$. C, The VIP-1 amacrine cell is GABAergic. Scale bar, $10 \mu \mathrm{m}$. D, A VIP-1 amacrine cell with "tail" (yellow arrow). Soma and ON arbors are labeled in green and OFF arbors are labeled in red. Scale bar, $100 \mu \mathrm{m}$.

(Fig. $6 A-F)$. The soma was $13.9 \pm 1.3 \mu \mathrm{m}$ in diameter $(n=10$ cells from 10 retinas) and located in the GCL. Two sets of arbors stratified in two layers: sparse, axon-like arbors intersected each other near the soma before extending across the entire retina near the bottom of the IPL; and small, thick arbors crossed the IPL in the distal direction and ramified at the INL/IPL border. Both nNOS-1 and CRH-2 amacrine cells were labeled by a nNOS antibody (Fig. $6 H, I$ ) and, thus, are likely to be the same cell type.

The somata of the second type of amacrine cell (nNOS-2) were $12.0 \pm 2.0 \mu \mathrm{m}$ in diameter $(n=8$ cells from 3 retinas $)$ and located in either the INL $(\sim 75 \%$ of the sample) or the GCL ( $\sim 25 \%$ of the sample). nNOS-2 cell processes arborized in the middle of the IPL midway between the upper and lower ChAT bands. We were unable to label nNOS-2 amacrine cells without also labeling nNOS-1 cells. This is most likely because nNOS-1 amacrine cell processes were located closer to the viral entry site and were thus preferential targets for viral infection. However, the layer-specific distribution of these two types allowed us to make a clean separation. Figure $6 J$ shows three nNOS-2 amacrine cells reconstructed from a whole-mount retinal image stack that spanned the IPL. nNOS-2 cells had a simple morphology. A single primary arbor descended vertically to the middle of the IPL and branched into 2-3 straight, thick primary processes (Fig. $6 K-M$ ). These processes branched again near the soma and typically spread in two groups of relatively straight arbors running in the opposite directions (Fig. 6J). The arbors were $\sim 1.5 \mathrm{~mm}$ long and strictly monostratified in the middle of the IPL ( $47 \pm 3 \%$ of the IPL, SL5; Fig. $6 K-M)$. nNOS-2 cells resemble the previously identified "bifid" cell (Badea and Nathans, 2004). Both nNOS-1 and nNOS-2 cells were GABAergic (Fig. 6G,N).

\section{The SST-ires-Cre driver targets starburst and one type of displaced wide-field amacrine cell}

One of the types of amacrine cells identified in the SST-ires-Cre driver line was distributed circumferentially in the retina, and had somata displaced in the GCL. These cells (SST-1) appeared to constitute a single morphological type. A large soma $(15.6 \pm 2.0 \mu \mathrm{m}$ diameter, $n=17$ cells from 17 retinas) gave rise to 2-3 thick "dendrite-like" processes and one long, fine axonlike process (Fig. $7 A-C$ ). The dendrite-like arbors typically branched once and then extended in a zigzag pattern (Fig. $7 C$ ). These arbors were $200 \mu \mathrm{m}$ long and ramified at the GCL border $(88 \pm 10 \%$ of the IPL, SL9-SL10; Fig. $7 D)$. The axon-like arbor and its branches started off near the GCL border $(86 \pm 9 \%$, SL8-SL10; Fig. 7E), traveled across the width of the IPL with or without an intermediate transition in the middle of IPL (Fig. 7F), and ended by ramifying at the INL border $(8 \pm 3 \%$, SL1-SL2; Fig. $7 G$ ). SST amacrine cells were GABAergic (Fig. $7 H$ ), but differed from CRH-2 and nNOS-1 amacrine cells in several ways. First, the soma was located in the retinal periphery instead of being evenly distributed as observed for CRH-2 and nNOS-1 amacrine cells. Second, the axon-like processes covered a smaller area of the retina. Third, and most important, the dendrite-like arbors stratified near the GCL and the long axon-like arbor terminated near the INL, an arrangement opposite to that observed for CRH-2 and nNOS-1 cells. SST-1 amacrine cells do not resemble previously described amacrine cell types (MacNeil and Masland, 1998; Badea and Nathans, 2004; Lin and Masland, 2006).

In addition to SST-1 cells, starburst amacrine cells (SACs) were also present in the GCL of the SST-ires-Cre driver. Since SACs are a major amacrine cell type in another Cre driver (CCKires-Cre), we will describe this cell type in the next section. 
The CCK-ires-Cre driver targets starburst and A17 cells

Although the broad labeling obtained in the Ai9 crosses usually makes cell type identification difficult, the amacrine cells labeled in the CCK-ires-Cre line belonged to well studied classes and were thus easy to identify. A displaced amacrine cell type had the distinctive morphology of SACs (Fig. 7I), which release both GABA and acetylcholine. SACs provide a critical inhibition that underlies the computation of directional selectivity in the retina. Immunostaining with an antibody directed against ChAT showed that $59 \pm 9 \%$ of the SACs in the GCL and $30 \pm 9 \%$ SACs in the INL expressed Cre (Fig. 7 J, K, $n=667$ cells for the GCL, $n=586$ cells for the INL, from 6 retinas). This observation suggests that molecular heterogeneity might exist within SACs. Cre-positive SACs accounted for approximately half (45 \pm $7 \%, n=870$ cells from 6 retinas) of the Cre-positive cells in the GCL.

The A17, a well studied amacrine cell type involved in the rod pathway, was also labeled in the CCK-ires-Cre driver line. A17 cells had radial, thin, nonbranching processes $(\sim 400 \mu \mathrm{m}$ long, $n=5$ cells from 5 retinas) with numerous varicosities at regular intervals (Fig. $7 L$, top). The processes emerged from soma in the INL and descended rapidly to ramify in a band near the GCL $(90 \pm 2 \%$ of the IPL, SL10; Fig. $7 L$, bottom).

\section{Cre-expression in RGCs}

Although the Cre-driver lines were designed to label GABAergic interneurons, we also observed labeling in ganglion cells, which are excitatory projection neurons, in three lines: $C R H$-ires-Cre, SST-ires-Cre, and CCK-ires-Cre. We proceeded to individually label and characterize the anatomy of these ganglion cells for three reasons: first, to distinguish them from displaced amacrine cells; second, to provide a more complete picture of the inner retinal cells labeled in each line; and, third, to facilitate ganglion cell typespecific manipulations.

Our first step in this characterization was to separate Creexpressing RGCs from other cell types, especially the wide-field amacrine cells, whose processes might interfere with RGC reconstruction. To accomplish this, we applied two different strategies. First, if ganglion cell labeling was sparse in the Ai9 cross, we focused solely on ganglion cells by crossing each Cre driver line with a Thy1-STOP-YFP mouse line (line 15; Buffelli et al., 2003) instead of the Ai9 reporter line. Thy1-STOP-YFP mice express EYFP under the control of the Thy-1 (mouse thymus cell antigen 1 , theta) promoter in a Cre-dependent manner. Thy- 1 is predominantly expressed in the axons of mature neurons. In the retina, immunohistochemistry shows that $70 \%$ of the Thy- 1 label colocalizes with RGCs, whereas the rest colocalizes with amacrine and bipolar cells (Perry et al., 1984). Usually, expression of EYFP is blocked by a loxP-flanked STOP cassette inserted between the promoter and the EYFP gene. However, when crossed with Cre drivers, Cre-mediated recombination between loxP sites results in excision of the STOP cassette and subsequent expression of EYFP. We expected that breeding each Cre driver into a Thy1STOP-YFP 15 background would lead to an expression of EYFP that is largely confined to ganglion cells. Second, if ganglion cell labeling was dense, we injected eyes with rAAV encoding for a floxed TVA and then transduced RGCs from their axonal terminals in a retino-recipient zone with EnvA-SAD $\Delta$ G-GFP, without infecting amacrine and other cell types in the retina.

As expected, crossing into a Thy1-STOP-YFP background removed most labeled amacrine cells from each Cre-driver line. In fact, two lines, VIP-ires-Cre and nNos-ires-CreER, no longer contained labeled cells, in agreement with a restricted expression of Cre to amacrine cells. In the CRH-ires-Cre, SST-ires-Cre, and CCK-ires-Cre driver lines, most amacrine cell labeling disappeared, whereas RGC labeling persisted (Fig. 8A). Among these three driver lines, the $C R H$-ires-Cre line displayed the sparsest labeled RGCs, the structures of which could be analyzed without 


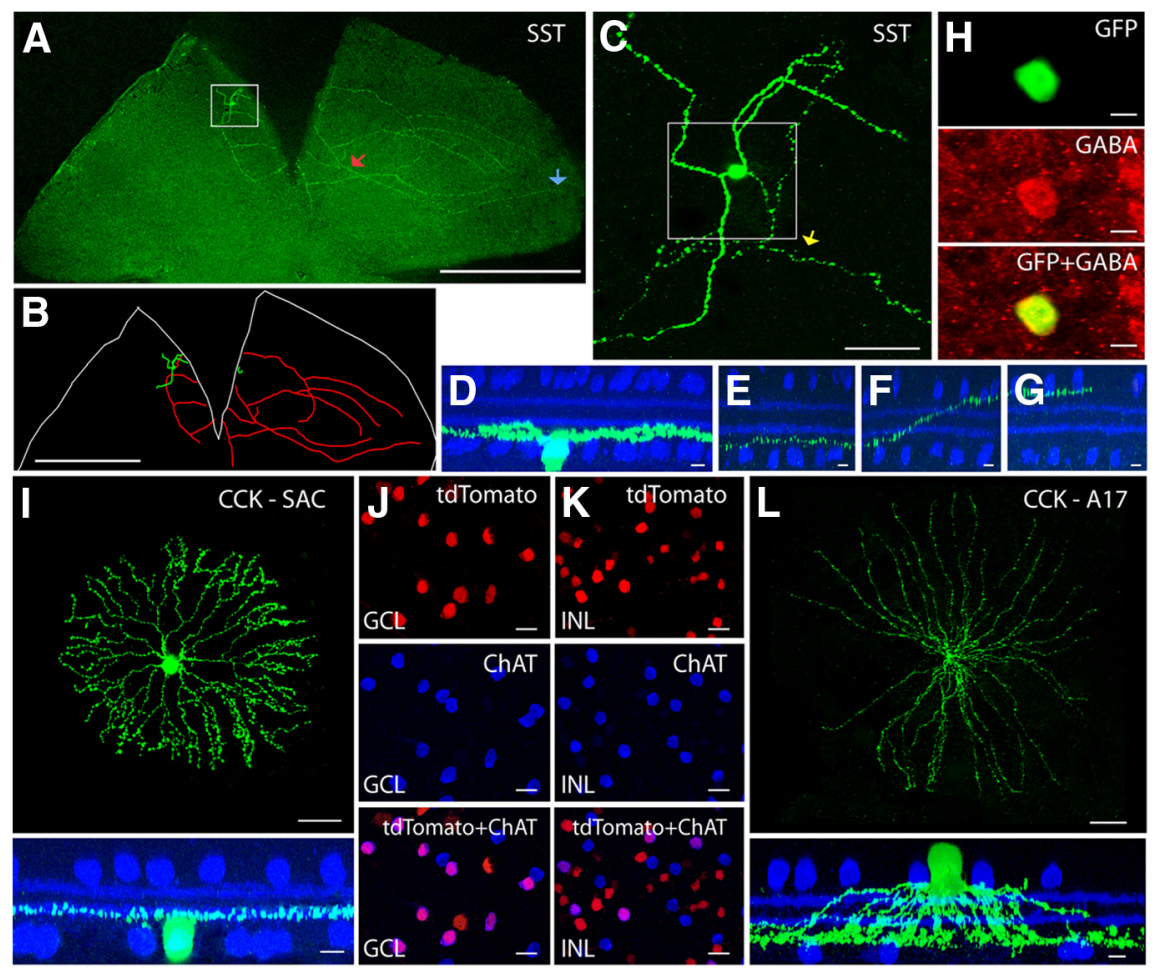

Figure 7. Labeling in the SST-ires-Cre and CCK-ires-Cre driver lines. $\boldsymbol{A}, \mathrm{A}$ flat-mounted retina with a single-labeled SST-1 amacrine cell. Scale bar, $1 \mathrm{~mm}$. $\boldsymbol{B}$, Neurolucida tracing of $\boldsymbol{A}$, with the dendrites and soma drawn in green, the axon-like processes drawn in red, and the outline of the retina marked in white. Scale bar, $1 \mathrm{~mm}$. $\boldsymbol{C}$, Enlarged view of the boxed region in $\boldsymbol{A}$. Scale bar, $50 \mu \mathrm{m}$. D, The side views with ChAT (blue) of the boxed region in $\boldsymbol{C}$, including the soma, dendrites, and axon-like processes. Scale bars, $10 \mu \mathrm{m}$. $\boldsymbol{E}-\boldsymbol{G}$, An axon-like process starts near the $\mathrm{GCL}(\boldsymbol{E}$, marked with the yellow arrow in $\boldsymbol{C})$, extends across the IPL ( $\boldsymbol{F}$, red arrow in $\boldsymbol{A}$ ), and finally runs near the INL ( $\boldsymbol{G}$, blue arrow in $\boldsymbol{A})$. Scale bars, $10 \mu \mathrm{m}$. $\boldsymbol{H}$, The SST-1 amacrine cell is GABAergic. Scale bar, $10 \mu \mathrm{m}$. I, The displaced amacrine cells in the CCK-ires-Cre driver are SACs. A GFP-labeled SAC is shown in the flat-mount view (top; scale bar, $50 \mu \mathrm{m}$ ), and the side view with ChAT (bottom; scale bar, $10 \mu \mathrm{m})$. $\boldsymbol{J}, \boldsymbol{K}$, Cre-positive SACs in the GCL $(\boldsymbol{J})$ and INL $(\boldsymbol{K})$. A retina from a CCK-ires-Cre $\times$ Ai9 mouse was stained with antibody against ChAT. Note that only a fraction of the SACs (labeled with ChAT) express Cre in the CCK-ires-Cre driver line. Scale bars, $20 \mu \mathrm{m}$. L, A17 amacrine cells were targeted in the CCK-ires-Cre driver line. An A17 cell was labeled with GFP. The flat-mount view is shown in the top (scale bar, $100 \mu \mathrm{m}$ ) and the side view with ChAT labeling is shown in the bottom (scale bar, $10 \mu \mathrm{m}$ ).

further isolation. Both the CCK-ires-Cre and SST-ires-Cre driver lines had densely labeled RGCs that required further segregation. Since SST-RGCs appear to comprise a large number of cell types, we focused our analysis on the CRH-RGCs and CCK-RGCs. Our classification of RGCs was based on four parameters: soma size, dendritic stratification, dendritic field size in both the $\mathrm{ON}$ and OFF sublaminae, and the symmetry of the dendritic field. These parameters were quantitatively compared with previous publications before cell types were assigned.

\section{RGC subtypes in the $\mathrm{CRH}$-ires-Cre driver line}

In the CRH-ires-Cre driver line, RGCs comprised $8 \pm 2 \%$ of Cre-positive cells (Fig. 1C). Breeding into a Thyl-STOP-YFP 15 background efficiently removed labeling in many amacrine cells and increased the proportion of labeled RCGs to $48 \pm 7 \%$ ( $n=638$ cells from 8 retinas). EYFP-labeled RGCs were spaced far enough apart for us to perform single-cell reconstruction (Fig. 8B).

CRH-RGCs can be classified into three morphological types. More than 75\% of CRH-RGCs (named CRH-1 RGCs) had large somata $(21.1 \pm 2.4 \mu \mathrm{m}, n=17$ cells from 5 retinas $)$ and dendritic fields $(294 \pm 33 \mu \mathrm{m})$. The soma produced 3-7 primary dendrites that branched at acute angles (Fig. 8C,D, top). Detailed morphological analysis suggests that two subtypes may exist in this
CRH-1 RGC population. One type stratified in SL4 (37 $\pm 1 \%$ of the IPL; Fig. $8 C$, bottom), whereas the other type stratified in both SL4 and SL1-SL2 (Fig. 8D, bottom). The CRH-1 RGCs strongly resemble W7 RGCs (Kim et al., 2010) and functional OFF- $\alpha$ RGCs (Pang et al., 2003), corresponding to A2 (Sun et al., 2002), cluster 7 (Badea and Nathans, 2004), cluster 10 (Kong et al., 2005), M9 (Coombs et al., 2006), G3 (Völgyi et al., 2009), and tOFF- $\alpha$ RGCs in CB2-GFP mice (Huberman et al., 2008).

The second population of CRH-RGCs (CRH-2 RGCs) was highly asymmetric, with structural features strongly resembling JAM-B RGCs (Kim et al., 2008). Somata were relatively small $(12.4 \pm 1.2 \mu \mathrm{m}$, $n=11$ cells from 5 retinas), and all of the dendrites lay on the ventral side of the soma and pointed in a ventral direction with a slight nasal bias (Fig. $8 E$, top). The soma gave off 1-2 primary dendrites that branched a few times in the middle of the IPL before further branching and terminating between SL2 and SL3 (14 $\pm 3 \%$ of the IPL; Fig. $8 E$, bottom).

The third population (CRH-3 RGCs) shared similarities with CRH-2 RGCs, in that both had asymmetric dendritic arbors pointing in the ventral direction (Fig. $8 F$, top). However, several major differences existed between the two subtypes. First, CRH-3 RGCs had much larger somata $(20.5 \pm 3.6 \mu \mathrm{m}, n=11$ cells from 5 retinas). Second, the area of the $\mathrm{CRH}-3$ RGC dendritic field $\left(\sim 58,000 \mu \mathrm{m}^{2}\right)$ was three times larger than that of the $\mathrm{CRH}-2$ RGC $\left(\sim 19,000 \mu \mathrm{m}^{2}\right)$. Third, the CRH-3 RGC stratified within a narrow band in SL4 (37 $\pm 3 \%$ of the IPL; Fig. $8 F$, bottom), below the stratum where $\mathrm{CRH}-2 \mathrm{RGC}$ dendrites resided.

CRH-RGC axon terminals projected to the deep regions of the retino-recipient zones in both the SC and dLGN (Fig. 8G). To label the RGC axon terminals in the brain, we injected the eyes with rAAV2 carrying Cre-dependent GFP ( $r A A V 2$ (YF4)$C B A-D I O-G F P)$. We injected CTb-594 in the same eye to mark the entire retino-recipient zone. Notably, a majority of the GFPlabeled axons originated from CRH-1 RGCs (presumably OFF$\alpha$ RGCs), which make up $>75 \%$ of CRH-RGCs (CRH-2 and CRH-3 RGCs make up the remaining 25\%). Therefore, in addition to the soma and dendritic morphology, the axonal projection pattern of this type of CRH-RGC was also consistent with OFF- $\alpha$ RGCs (Huberman et al., 2008; Kim et al., 2010).

\section{RGC subtypes in the CCK-ires-Cre driver line}

In CCK-ires-Cre $\times$ Thyl-STOP-YFP XV mice, EYFP-labeled RGCs were so dense that almost every cell had dendritic arbors that overlapped with neighbors. To achieve a sparser labeling of RGCs, we returned to the EnvA-SAD $\Delta G-G F P$ labeling strategy. In this case, however, we injected EnvA-SAD $\Delta G$-GFP into the retino-recipient regions (SC or LGN) instead of the eyes (Fig. 9A). This strategy allows TVA-expressing RGCs to take up EnvA- 
SAD $A$ G-GFP through their axonal terminals and removes the opportunity for labeling of other retinal cell types. As before, the density of labeled RGCs was controlled by adjusting the doses of rAAV2(YF4)-CBA-DIO-TVA and EnvA$S A D \Delta G-G F P$. As expected, $6 \mathrm{~d}$ after EnvA$S A D \Delta G-G F P$ injection, RGCs were exclusively labeled with GFP at a low density, allowing for single-cell reconstruction (Fig. 9B). Close examination revealed three subtypes of GFP-labeled RGCs: two bistratified and one monostratified. No differences in the RGC labeling pattern were observed between the SC and LGN injections.

The most abundant CCK-RGCs (named CCK-1 RGCs; $70 \%$ of the sample, $n=28$ cells from 8 retinas) were small bistratified RGCs. Their dendritic arbors were positioned at $67 \pm 4 \%$ (SL7-SL8) and $18 \pm 6 \%$ (SL2-SL3) of the IPL, and partially overlapped with the ChAT-positive bands (Fig. 9C, bottom). Compared with the ON-OFF direction-selective ganglion cells (DSGCs) described below, this type of RGCs has a smaller dendritic field and more broadly stratified dendritic arbors that extend closer to the nuclear layers (INL and GCL). Notably, $\sim 50 \%$ of the processes in the ON layer originated from dendrites that had already traveled down to the OFF layer and then climbed back to the ON layer. This structural arrangement led to a "broken" appearance in the flatmount view as well as many crossing branches in the side view (Fig. 9C). These unique morphological features bear a strong resemblance to the recently identified s-BGCs in a PCP2Cre mouse line (Ivanova et al., 2013).

The second most abundant CCK-RGCs (CCK-2 RGCs; 20\% of the sample, $n=12$ cells from 8 retinas) were the well characterized ON-OFF DSGCs. The ON and OFF dendrites arborized at $61 \pm 3 \%$ (SL6-SL7) and $29 \pm 4 \%$ (SL3-SL4) of the IPL, respectively, completely costratifying with the ChAT-positive bands (Fig. 9D,E, bottom). The dendritic arbors could be symmetric (Fig. 9D, top), or asymmetric (Fig. 9E, top). The symmetric RGCs have similar sizes of $\mathrm{ON}$ and OFF dendritic fields. In the asymmetric cells, the OFF dendritic field was $80 \%$ larger than the ON field (Table 3). The dendrites in asymmetric RGCs pointed in the ventral direction, consistent with BD-RGCs (Kay et al., 2011b) and Hb9+ DSGCs (Trenholm et al., 2011).

The third type of RGC in the CCK-ires-Cre driver line (CCK-3 RGCs, $10 \%$ of the sample, $n=10$ cells from 8 retinas) was a type of monostratified cell with a large dendritic field $(\sim 340 \mu \mathrm{m}$ in diameter). CCK-3 RGCs had 4-7 smooth primary dendrites that branched without overlapping (Fig. $9 F$, top). The dendrites were monostratified and occupied a narrow band at $83 \pm 5 \%$ of the IPL (SL8-SL9; Fig. 9F, bottom). These morphological features strongly resemble those of ON- $\alpha$ RGCs in mice (Pang et al., 2003).

The axons of CCK-RGCs projected to retino-recipient zones in the SC, dLGN, and vLGN (ventral lateral geniculate nucleus;
Fig. $9 G$ ), as well as the nucleus of optic tract, medial terminal nucleus, and dorsal terminal nucleus (data not shown). In the SC, vLGN, and dLGN, robust GFP-labeled terminals were observed in a thin superficial layer. In this study, we restricted our retrograde labeling of RGCs to the SC and LGN. Since $70-100 \%$ of RCGs project to the SC (Hofbauer and Dräger, 1985), it is likely that we labeled all the Cre-positive RCG types. However, we cannot exclude the possibility that some RCGs do not project to either the SC or LGN, in which case these neurons would not be retrogradely labeled by our injections.

\section{Evaluation of the completeness of labeling of Cre-positive cell types}

Our next step was to verify whether the virus-identified cell types represent most or all of the Cre-expressing cell types in these driver lines. To evaluate the completeness of labeling, we crossed each Cre driver line with the Ai9 reporter mice and measured the distributions of tdTomato-labeled (i.e., Cre-positive) soma diameters. We next determined whether the cell types identified with rAAV/EnvA rabies virus (or Thy1-STOP-YFP 15 crossing for CRH-RGCs) were representative of the same distributions. In addition, for Cre driver lines that had labeling in discrete IPL strata, we compared the labeled strata in Cre $\times$ Ai9 crosses with those of cells labeled with rAAV/EnvA rabies virus. Although unlikely, it is possible, that this analysis would not distinguish 


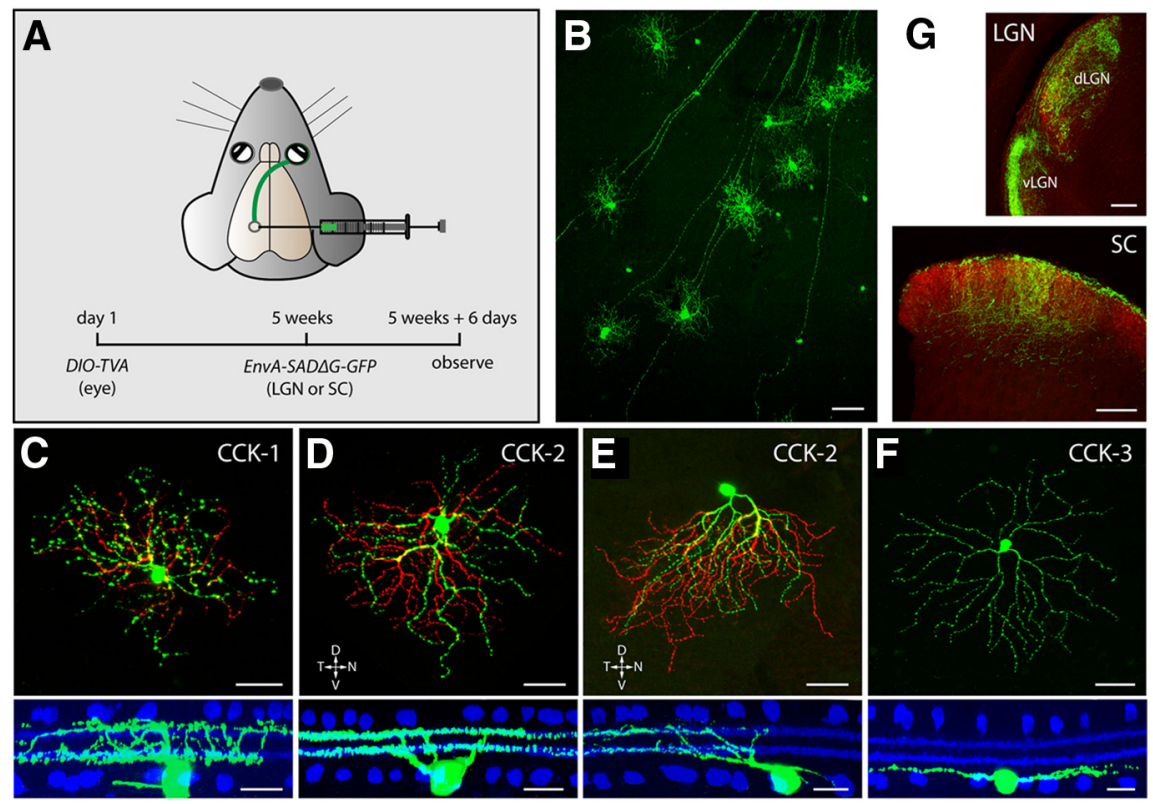

Figure 9. Cre-expressing RGCS in the CCK-ires-Cre driver line. $\boldsymbol{A}$, Strategy using rAAV/EnvA rabies virus to label CCK-RGCS from axonal terminals. $\boldsymbol{B}$, GFP-labeled CCK-RGCs in a flat-mount retina from a CCK-ires-Cre mouse. Scale bar, $100 \mu \mathrm{m}$. $\boldsymbol{C}-\boldsymbol{F}$, Morphology of different types of CCK-RGCs. Flat-mount view of each type of RGC (green) are shown in the top, with soma and ON arbors labeled in green and OFF arbors pseudocolored in red. Scale bar, $50 \mu \mathrm{m}$. Side views with ChAT-band (blue) are shown in the bottom. Scale bars, $20 \mu \mathrm{m}$. G, Coronal view of CCK-RGC axonal terminals in the SC, the dLGN, and the vLGN. All RGC axons from both eyes are labeled with CTb-594 (red); CCK-RGC axons are labeled with GFP (green). Scale bar, $200 \mu \mathrm{m}$.

between two amacrine or ganglion cell types with nearly the same soma size and dendrite stratification level.

To simplify the analysis, we first sorted tdTomato-labeled cells in Cre $\times$ Ai9 mice into two populations, GABAergic (presumptive amacrine cells) and non-GABAergic, by labeling the retina with an antibody against GABA. The non-GABAergic cells were presumed to be RGCs insofar as immunohistochemistry showed that they also lacked glycine (data not shown), another amacrine cell transmitter. In two lines, VIP-ires-Cre and $n N O S$-ires-CreER, nearly all tdTomato-labeled cells were GABAergic (Fig. 10A, $B$ ), consistent with the restricted expression of Cre to amacrine cells. In the INL of the VIP-ires-Cre driver $(n=154$ cells from 4 retinas), and separately in the GCL ( $n=330$ cells from 4 retinas) and INL ( $n=402$ cells from 4 retinas) of the $n N O S$-ires-CreER driver, the soma diameters were well fitted with single Gaussian distributions, each with a mean and SD similar to those obtained from neurons labeled by rAAV/EnvA rabies virus in the same lines (Fig. $10 A, B$, Tables 2, 4). In addition, in the VIP-ires-Cre driver, vertical sections showed that the strata labeled in the Ai9 cross occupied two major bands (SL1-SL3 and SL6-SL8), similar to the virus-labeled VIP-1 amacrine cell (Fig. 5, Table 2). Thus, the rAAV/EnvA rabies virus may label all of the Cre-positive amacrine cell types in the VIP-ires-Cre and $n N O S$-ires-CreER lines.

In three other lines, CRH-ires-Cre, SST-ires-Cre, and CCKires-Cre, Cre expression was localized to both GABAergic and non-GABAergic cells (Fig. 10C-E), consistent with Cre expression in both amacrine cells and RGCs. In the CRH-ires-Cre driver, the soma diameters of the GABAergic cells were well fitted with two Gaussian functions which had peak diameters that closely matched those of CRH-1 and CRH-2 amacrine cells (Fig. $10 C, n=306$ cells from 5 retinas; Tables 2,4$)$. The soma diameters of the non-GABAergic cells (Fig. 10C, $n=146$ cells from 5 retinas; Tables 2, 4) in the $\mathrm{CRH}$-ires-Cre driver were separated into two distinct populations, one small (peak diameter $=12.5 \pm$ distribution of soma diameters that were well fitted by two Gaussian functions. The larger population of cells $(91 \pm 3 \%, n=$ 216 cells) had a diameter of $15.4 \pm 3.7 \mu \mathrm{m}$, whereas the remaining cells ( $9 \pm 2 \%, n=21$ cells) could be grouped into a population with a diameter of $20.5 \pm 2.3 \mu \mathrm{m}$. The soma diameter of the first population is in agreement with that found for the CCK-1 RGCs (Fig. 9C, Tables 3, 4), which were the most abundant RGCs in our classification. The second population matched a mixture diameter of the CCK-2 and CCK-3 RGC somata (Fig. 9D-F, Tables 3,4$)$. Therefore, three RGC types identified by retrograde labeling from the SC and LGN could explain the two peaks in the distribution of GABA-lacking RGCs.

In the SST-ires-Cre driver, the GCL contained both SACs (68\% of the GABAergic cells) and non-SAC GABAergic cells ( $32 \%$ of the GABAergic cells; $n=334$ cells from 6 retinas). The somata of non-SAC GABAergic cells $(n=107$ cells from 6 retinas) showed a distribution that was fitted with two Gaussians. One Gaussian peak had a diameter of $15.4 \pm 1.6 \mu \mathrm{m}$, corresponding to that of the SST-1 amacrine cells (Fig. 7A-G, Tables 2, 4). The remaining non-SAC GABAergic cells had a soma diameter of $11.9 \pm 2.1 \mu \mathrm{m}$. Our viral strategy did not label an amacrine cell type with a soma diameter in the range of $11.9 \mu \mathrm{m}$ and, thus, at least one cell type may be absent from our viral classification. In summary, our rabies virus-based cell type characterization identified most of the Cre-expressing cells in three driver lines, CRH-ires-Cre, VIP-ires-Cre, and nNOS-ires-CreER, and in the GCL layer of a fourth, CCK-ires-Cre driver line. In addition, our approach identified most of the displaced amacrine cells in the fifth SST-ires-Cre driver line.

The rAAV/EnvA rabies virus approach identifies specific cell types in other brain regions

The Cre driver lines analyzed in this study were originally designed to target cortical GABAergic neurons (Taniguchi et al., 
Table 3. Summary of RGC types in Cre driver lines

\begin{tabular}{|c|c|c|c|c|c|}
\hline Cre driver & Cell type & Soma diameter $(\mu \mathrm{m})$ & Dendritic field diameter $(\mu \mathrm{m})$ & Symmetry index & Dendritic stratification (\% in IPL) \\
\hline $\mathrm{CRH}$ & (RH- 1 RGC ${ }^{a}(n=17$ from 5 retinas) (OFF- $\alpha$ RGC) & $21.1 \pm 2.4$ & $294 \pm 33$ & $0.09 \pm 0.05$ & $37 \pm 1$ (off) \\
\hline CRH & $\mathrm{CRH}_{-2} \mathrm{RGC}^{b}$ ( $n=11$ from 5 retinas) (JAM-B RGC) & $12.4 \pm 1.2$ & $177 \pm 32$ & $0.45 \pm 0.02$ & $14 \pm 3$ (off) \\
\hline $\mathrm{CRH}$ & CRH-3 RGC ( $n=11$ from 5 retinas) & $20.5 \pm 3.6$ & $247 \pm 31$ & $0.33 \pm 0.07$ & $37 \pm 3$ (off) \\
\hline \multirow[t]{2}{*}{ CCK } & $\mathrm{CCK}^{-1} \mathrm{RGC}^{\mathrm{C}}(n=28$ from 8 retinas) (S-BGC) & $15.6 \pm 2.2$ & $192 \pm 35$ (on) & $0.09 \pm 0.06$ (on) & $67 \pm 4$ (on) \\
\hline & & & $161 \pm 28$ (off) & $0.10 \pm 0.05$ (off) & $18 \pm 6$ (off) \\
\hline \multirow[t]{2}{*}{ CCK } & $\mathrm{CCK}-2 \mathrm{RGC}^{d}$ ( $n=12$ from 8 retinas) DSGC (Symm) & $17.9 \pm 3.3$ & $268 \pm 80$ (on) & $0.13 \pm 0.06$ (on) & $61 \pm 3$ (on) \\
\hline & & & $254 \pm 69$ (off) & $0.08 \pm 0.07$ (off) & $29 \pm 4$ (off) \\
\hline \multirow[t]{2}{*}{ CCK } & $\mathrm{CCK}^{-2} \mathrm{RGC}^{e}(n=11$ from 8 retinas) BD-RGC & $17.9 \pm 3.4$ & $194 \pm 53$ (on) & $0.37 \pm 0.08$ (on) & $61 \pm 2$ (on) \\
\hline & & & $268 \pm 39$ (off) & $0.29 \pm 0.09$ (off) & $28 \pm 2$ (off) \\
\hline CCK & CCK-3 $\operatorname{RGC}^{f}(n=10$ from 8 retinas) (0N- $\alpha \mathrm{RGC})$ & $18.6 \pm 6.6$ & $343 \pm 82$ & $0.07 \pm 0.04$ & $83 \pm 5$ (on) \\
\hline
\end{tabular}

Data are presented as mean \pm SD. Equivalent cells are indicated in footnotes $a-f$.

${ }^{a}$ W7 RGCs (Kim et al., 2010); OFF- $\alpha$ RGCS (Pang et al., 2003); A2 (Sun et al., 2002); cluster 7 (Badea and Nathans, 2004); cluster 10 (Kong et al., 2005); M9 (Coombs et al., 2006 ); G3 (Volgyi et al., 2009); tOFF- $\alpha$ RGCs in CB2-GFP mice (Huberman et al., 2008).

${ }^{b} J A M-B$ RGCS (Kim et al., 2008).

s-BGCs (Ivanova et al., 2013).

${ }^{d}$ D2 (Sun et al., 2002); Bistratified cluster 2 (Badea and Nathans, 2004); M12 and M13 (Coombs et al., 2006); G17 (Volgyi et al., 2009).

eBD-RGCs (Kay et al., 2011); Hb9 + DSGCs (Trenholm et al., 2011).

fON- $\alpha$ RGCs (Pang et al., 2003).

2011). To verify that the rAAV/EnvA rabies virus approach can be used to sparsely label and identify specific cell types in the cerebral cortex and other brain regions, we used our approach on the CCK-ires-Cre and SST-ires-Cre drivers and focused on five regions: M1, S1, V1, LGN, and SC. First, rAAV2(YF4)-CBA-DIOTVA was injected into each brain region in double-transgenic Cre driver $\times$ Ai9 mice. Three weeks after rAAV injection, EnvA$S A D \Delta G-G F P$ was injected into the same site. The brain was examined $7 \mathrm{~d}$ later. We verified the targeted expression of GFP in Cre-expressing cells by observing somatic coexpression of GFP and tdTomato. As in the retina, there was an optimal viral dose for sparse neuronal labeling that varied with Cre driver line and brain region (Table 1). For the CCK-ires-Cre driver, sparse labeling was routinely achieved when $1.5 \times 10^{9}$ genome copies of rAAV and 300 IU of EnvA-SAD $\Delta G$-GFP were injected into $\mathrm{M} 1, \mathrm{~S} 1, \mathrm{~V} 1$, and SC. To label the same brain regions in the $S S T$-ires-Cre driver required the same amount of $\operatorname{rAAV}(1.5 \times$ $10^{9}$ genome copies) combined with tenfold less EnvA$S A D \Delta G-G F P$ (30 IU). On the other hand, to label LGN in both $C C K$-ires-Cre and SST-ires-Cre drivers, a higher dose of EnvA$S A D \Delta G$-GFP $\left(3 \times 10^{3} \mathrm{IU}\right)$ was required when $1.5 \times 10^{9}$ genome copies of rAAV were injected. Under the appropriate conditions, single-cell morphology could be routinely revealed in each brain region (Fig. 11).

rAAV/EnvA rabies virus facilitates cell type-specific functional imaging and optogenetic manipulation

We have so far used the rAAV/EnvA rabies virus strategy to label individual neurons for anatomical characterization. However, the large capacity of the rabies virus genome $(\sim 10 \mathrm{~kb})$ makes it suitable for expressing a wide range of genetic and optogenetic tools (Osakada et al., 2011). To test the feasibility of using the $\mathrm{rAAV} /$ EnvA rabies virus approach for functional studies, we replaced GFP with either a genetically encoded calcium indicator, GCaMP3 (Tian et al., 2009; Borghuis et al., 2011; Yonehara et al., 2013), or an optogenetic protein, ChR2-venus (Boyden et al., 2005; Petreanu et al., 2009).

We expressed GCaMP3 in both the amacrine and ganglion cells by making sequential intravitreal injections of $r A A V 2$ (YF4)CBA-DIO-TVA and EnvA-SADAG-GCaMP3 in the CRH-iresCre and CCK-ires-Cre driver lines (Fig. 12A-D). Light responses were elicited by a $565 \mathrm{~nm}$ LED flash $(200 \mathrm{~ms})$, and fluorescence responses were imaged with a two-photon microscope. Strong fluorescence responses were detected in both the soma and proximal processes of CRH-2 amacrine cells (Fig. 12A). The fluorescence transients were faster in the proximal processes compared with the soma, reflected by both the times to peak (Fig. 12B) and decay time constants (Fig. 12C). The light stimulus also evoked fluorescence transients in the somata of CCK-RGCs (Fig. 12D).

The feasibility of using EnvA-ChR2-venus to manipulate the membrane voltage of specific cell types was tested in the Creexpressing amacrine and ganglion cells in the $C R H$-ires-Cre driver. Intravitreal injection of $r A A V 2$ (YF4)-CBA-DIO-TVA followed by EnvA-SAD $\Delta G-C h R 2-v e n u s$ resulted in sparse labeling of multiple cell types. Illumination of ChR2-positive CRH-1 amacrine cells (Fig. 12E) and CRH-RGCs (Fig. 12F) with blue light briskly induced steady inward currents in both types.

The results show that $\mathrm{rAAV} /$ EnvA rabies virus-mediated expression of GCaMP3 and ChR2 can be used to monitor and manipulate neural activity in specific cell types.

\section{Discussion}

The use of Cre drivers in combination with either floxed reporter lines or viral delivery has revolutionized the study of neuronal processing by enabling the manipulation of specific neuron populations. With numerous Cre driver lines generated by individual laboratories and GENSAT (Gene Expression Nervous System Atlas), there is a need to characterize the cell type-specific patterns of Cre expression throughout the nervous system. Since the brain contains large numbers of cell types, even specific promoters usually target Cre expression to multiple cell types. Manipulations that involve several neuron types at once are less experimentally useful than those confined to a single type. Thus, it is important not only to screen Cre-driver lines to determine the labeled neuron types, but to develop methods to restrict labeling from several types to one.

\section{Comparison with other approaches}

We demonstrate that, in addition to its use in monosynaptictranssynaptic tracing, EnvA-pseudotyped rabies is useful for cell type-specific labeling. Our approach to labeling individual neuron types in living tissue offers several advantages over the traditional methods of intracellular tracer injection and newer rAAV approaches. Like tracer injection, EnvA-pseudotyped rabies pro- 
A
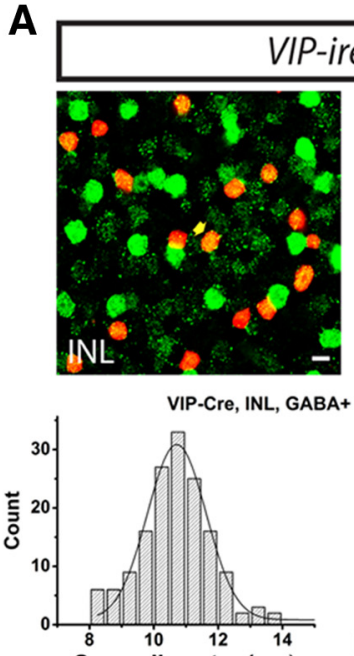

Soma diameter (um)

C
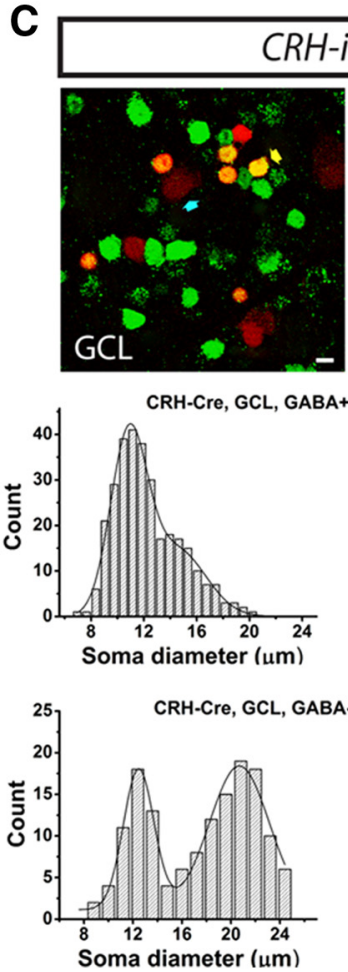

B

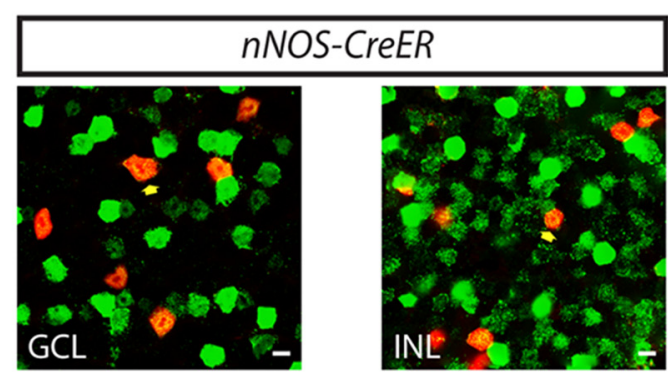

nNOS-CreER, GCL, GABA+
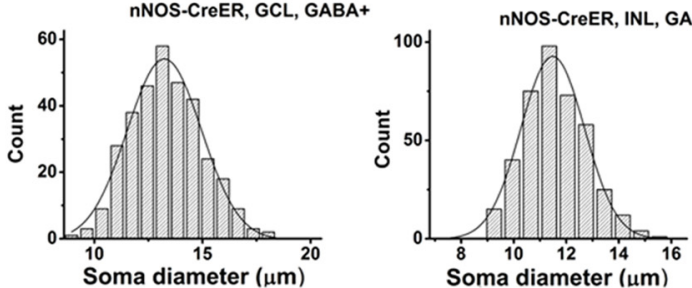

D

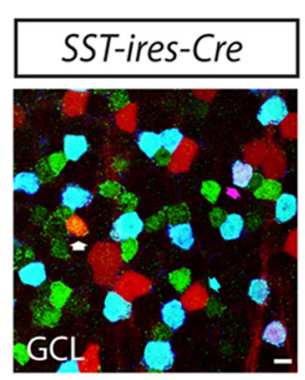

E
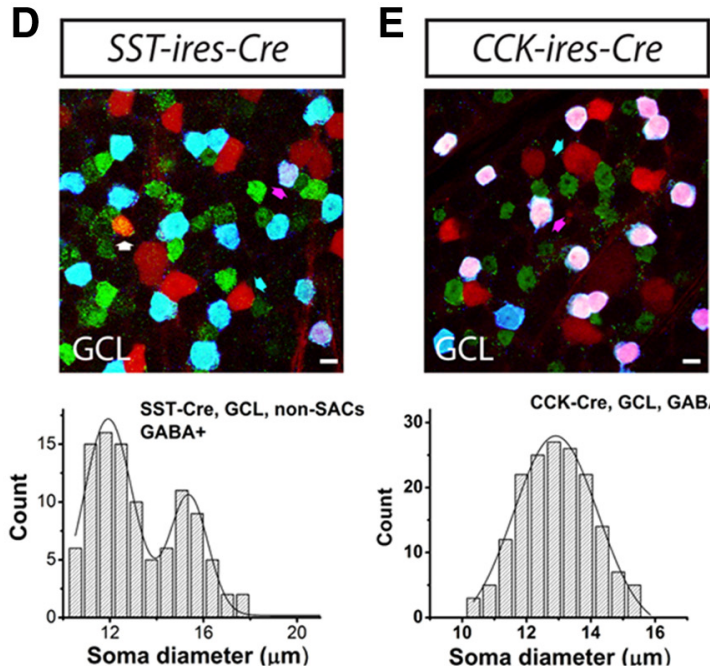

CCK-Cre, GCL, GABA-
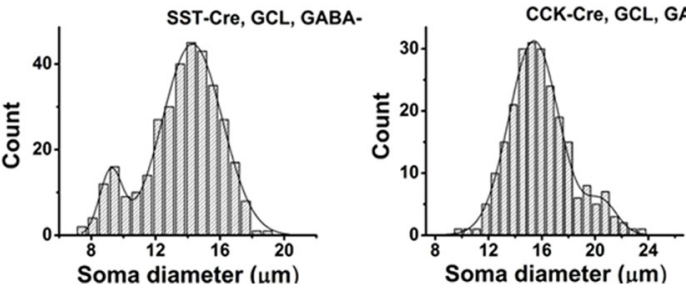

12345678910

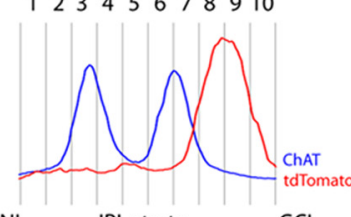

IPL strata $\mathrm{GCL}$

Soma diameter (um)

Figure 10. Evaluation of the completeness of labeling in Cre driver lines based on soma diameter and level of dendritic stratification. $\boldsymbol{A}-\boldsymbol{E}$, Five Cre driver lines, including VIP-ires-Cre $(\boldsymbol{A})$, nNOS-ires-CreER $(\boldsymbol{B})$, CRH-ires-Cre $(\boldsymbol{C})$, SST-ires-Cre $(\boldsymbol{D})$, and CCK-ires-Cre $(\boldsymbol{E})$, were crossed with Ai9 reporter mice (tdTomato; red), and the retinas were further stained with an antibody against GABA (green). $\boldsymbol{A}, \boldsymbol{B}$, All tdTomato-labeled cells were GABAergic (GABA+; yellow arrow shows an example of somatic colocalization). $C-E$, In addition to $G A B A e r g i c$ cells (yellow arrow), non-GABAergic cells (GABA - ; cyan arrow) were also observed, with somata labeled with tdTomato, but not GABA. D, E, GABAergic cells were further separated with an antibody against ChAT (blue). Cells labeled with tdTomato, GABA, and ChAT were SACs (pink arrow), whereas cells labeled with tdTomato and GABA but not ChAT were non-SAC GABAergic cells (white arrow). Evidently, all of the GABAergic cells in the CCK-ires-Cre retina were SACs. The soma diameters of GABAergic cells $(\boldsymbol{A}-\boldsymbol{C})$ in the INL $(\boldsymbol{A})$, GCL and INL $(\boldsymbol{B})$, and $\mathrm{GCL}(\boldsymbol{C})$, and non-GABAergic cells $(\boldsymbol{C}-\boldsymbol{E})$, SACS $(\boldsymbol{E})$, and non-SAC GABAergic cells $(\boldsymbol{D})$ in the $\mathrm{GCL}$ were measured and plotted as distribution histograms. The histograms were fitted with either single or double Gaussian curves (see Table 3 for fit parameters). The non-GABAergic cells (presumptive RGCS) in the SST-ires-Cre line (D) were omitted from our classification due to the high abundance of labeled cell types, but their soma sizes were analyzed here for completeness. The IPL strata in the VIP-ires-Cre and CRH-ires-Cre were further analyzed in $\boldsymbol{A}$ and $\boldsymbol{C}$. Vertical slices of the retinas were stained with an antibody against ChAT (blue), and 10 strata in the IPL were defined using the ChAT bands. Stratification of tdTomato-labeled arbors was quantified relative to the ChAT. Scale bar, $10 \mu \mathrm{m}$.

duces labeling of individual cells with a high signal-tobackground ratio. However, unlike tracer injection, a genetic approach provides a consistent supply of neurons belonging to a single type, and does so with minimal labor beyond that required to breed mice and inject eyes. In addition, due to strong expression and long equilibration time, EnvA-pseudotyped rabies fills the entire neuron, including very thin neurites, whereas tracer injection can lead to an incomplete fill. Newer rAAV approaches can produce brightly labeled cells with relatively little effort. However, because the rAAV genome does not replicate in cells (Deyle and Russell, 2009), efforts to produce sparse labeling by reducing rAAV titer may also result in decreased labeling intensity, assuming a relationship between cell transduction number and expression level. In contrast, EnvA-pseudotyped rabies virus 
Table 4. Comparison of cell types estimated from soma analysis and identified with rAAV/EnvA rabies virus or Thy1-STOP-YFP 15 crossing

\begin{tabular}{|c|c|c|c|c|}
\hline Cre driver & GABA expression & Fitting, number of Gaussians & Soma diameters from the fit $(\mu \mathrm{m})$ & Corresponding cell types \\
\hline CRH & GABAergic (ACs) & Two & $\begin{array}{l}10.8 \pm 2.8 \\
14.5 \pm 4.4 \\
\left(p=1.00, \chi^{2} \text { test }\right)\end{array}$ & $\begin{array}{l}\text { CRH-1 AC } \\
\text { CRH-2 AC }\end{array}$ \\
\hline CRH & non-GABAergic (RGCs) & Two & $\begin{array}{l}12.5 \pm 2.5 \\
20.7 \pm 4.9 \\
\left(p=0.98, \chi^{2} \text { test }\right)\end{array}$ & $\begin{array}{l}\text { CRH-2 RGC } \\
\text { CRH-1 RGC \& CRH-3 RGC }\end{array}$ \\
\hline VIP & GABAergic (ACs) & One & $\begin{array}{l}10.7 \pm 1.8 \\
\left(p=1.00, \chi^{2} \text { test }\right)\end{array}$ & VIP-1 AC \\
\hline nNOS & GABAergic (GCL) & One & $\begin{array}{l}13.2 \pm 3.4 \\
\left(p=0.84, \chi^{2} \text { test }\right)\end{array}$ & nNOS-1 AC \\
\hline nNOS & GABAergic (INL) & One & $\begin{array}{l}11.5 \pm 2.4 \\
\left(p=0.80, \chi^{2} \text { test }\right)\end{array}$ & nNOS-2 AC \\
\hline SST & non-SAC GABAergic (ACs) & Two & $\begin{array}{l}11.9 \pm 2.1 \\
15.4 \pm 1.6 \\
\left(p=0.99, \chi^{2} \text { test }\right)\end{array}$ & $\begin{array}{l}\text { N.0. } \\
\text { SST-1 AC }\end{array}$ \\
\hline SST & non-GABAergic (RGCs) & Two & $\begin{array}{l}9.2 \pm 1.4 \\
14.3 \pm 3.7 \\
\left(p=0.99, \chi^{2} \text { test }\right)\end{array}$ & NA \\
\hline CCK & GABAergic (ACs) & One & $\begin{array}{l}12.9 \pm 2.3 \\
\left(p=0.98, \chi^{2} \text { test }\right)\end{array}$ & SAC \\
\hline CCK & non-GABAergic (RGCs) & Two & $\begin{array}{l}15.4 \pm 3.7 \\
20.5 \pm 2.3 \\
\left(p=1.00, \chi^{2} \text { test }\right)\end{array}$ & $\begin{array}{l}\text { CCK-1 RGC } \\
\text { CCK-2 RGC \& CCK-3 RGC }\end{array}$ \\
\hline
\end{tabular}

rAAV injections were performed on 5- to 6-week-old mice. Data are presented as mean \pm SD. ACs, Amacrine cells; NA, not applicable; N.0., not observed.

retains the ability to replicate its genome; thus, robust labeling can still be achieved in an infected neuron when only one or a few viral particles are present. The ability to obtain robust yet sparse labeling proved critical for delineating the processes of individual wide-field amacrine cells, which can span the entire retina.

\section{Limitations of the rAAV/EnvA rabies virus approach}

A potential limitation of the rAAV/EnvA rabies virus approach is that labeling requires that both viruses have access to the target cell. Accessibility may be limited by virus size and penetration properties, neuron distance from the inner limiting membrane at the vitreal surface of the retina, and a recognition mismatch in the case of rAAV between the virus and the targeted cell. In fact, we were unable to label subsets of Creexpressing amacrine cells in the INL in three lines, including CRH-ires-Cre, SST-ires-Cre, and CCK-ires-Cre. Since most Creexpressing amacrine cells were located in the GCL in these three lines, the error produced by decreased access to INL somata is likely small. Future modifications of viral capsid proteins to produce better penetration (Dalkara et al., 2013) and recognition could extend the approach to cell types that currently cannot be revealed by rAAV/EnvA rabies virus.

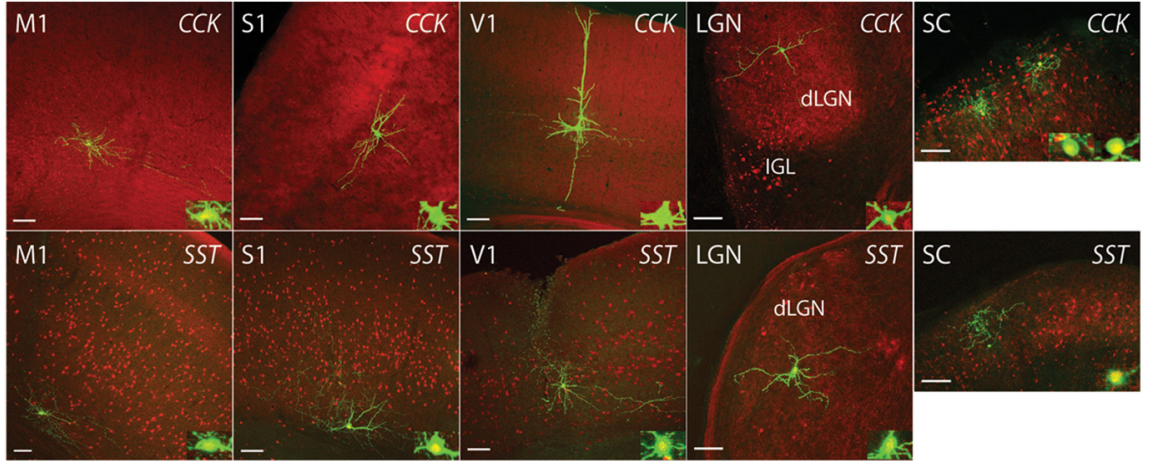

Figure 11. rAAV/EnvA rabies virus labels individual cells in the cerebral cortex and other brain regions. rAAV2(YF4)-CBA-DIOTVA (1.5 $\times 10^{9}$ genome copies) and EnvA-SAD $\triangle$ G-GFP were injected into M1, S1,V1, LGN, and SC in two Cre drivers crossed with the Ai9 reporter: CCK-ires-Cre $\times$ Ai9 and SST-ires-Cre $\times$ Ai9. The doses of EnvA-SAD $\Delta$ G-GFP injected into each region were: 300 IU for M1, S1, V1, and SC in CCK-ires-Cre driver; 30 IU for M1, S1, V1, and SC in SST-ires-Cre driver; and $3 \times 10^{3}$ IU for the LGN in both drivers. Cre expression in each region is revealed by tdTomato labeling (red); GFP labeling of individual cells is shown in green. Insets, Coexpression of GFP (green) and tdTomato (red) in the somata. Scale bars, $100 \mu \mathrm{m}$.

\section{Identification of amacrine cell types}

An unbiased, large-scale characterization of amacrine cells was first performed by MacNeil and Masland (MacNeil and Masland, 1998; MacNeil et al., 1999) in the rabbit retina with a photofilling technique. Subsequently, Badea and Nathans (2004) systematically surveyed amacrine cells in the mouse retina by randomly delivering a genetically directed alkaline phosphatase. This latter approach has been enormously useful for identifying rare cell types including wide-field amacrine cells. Later, Lin and Masland (2006) surveyed wide-field amacrine cells in a transgenic mouse 
A
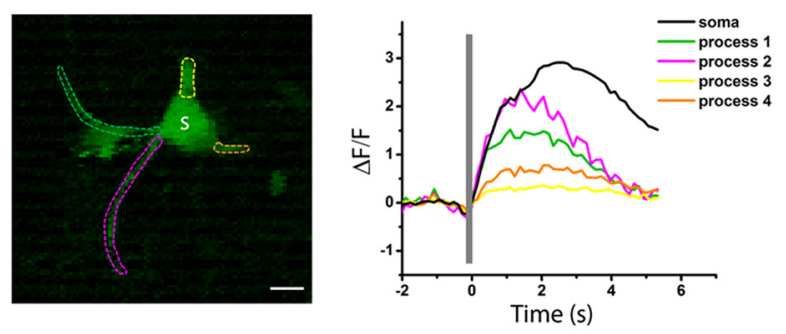

B
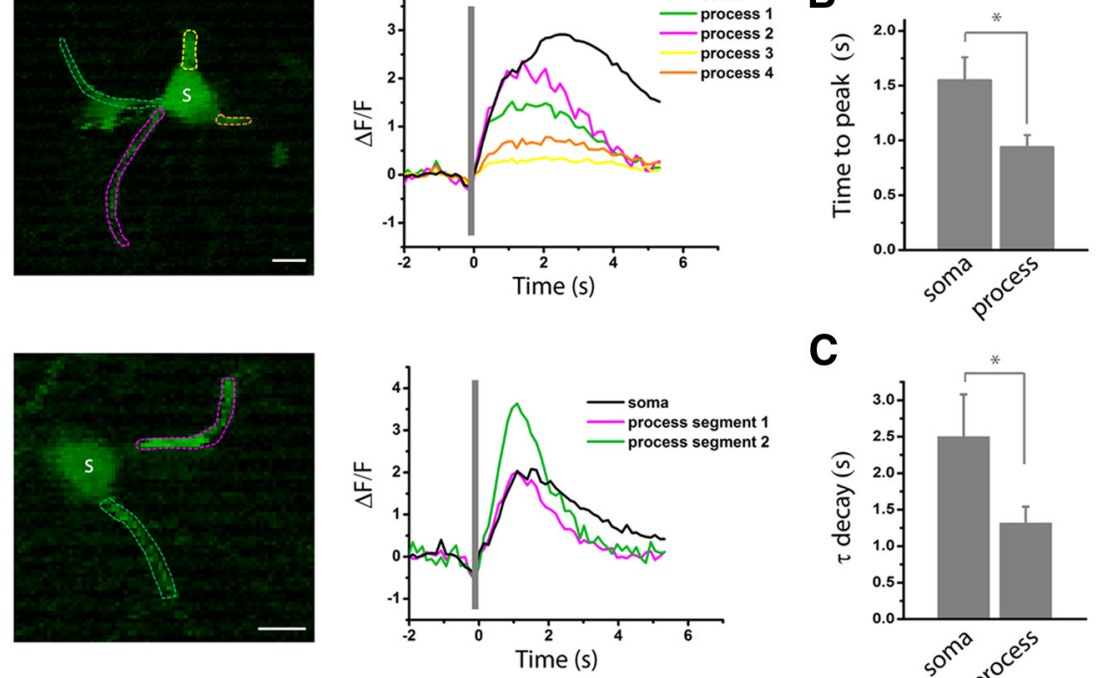

C
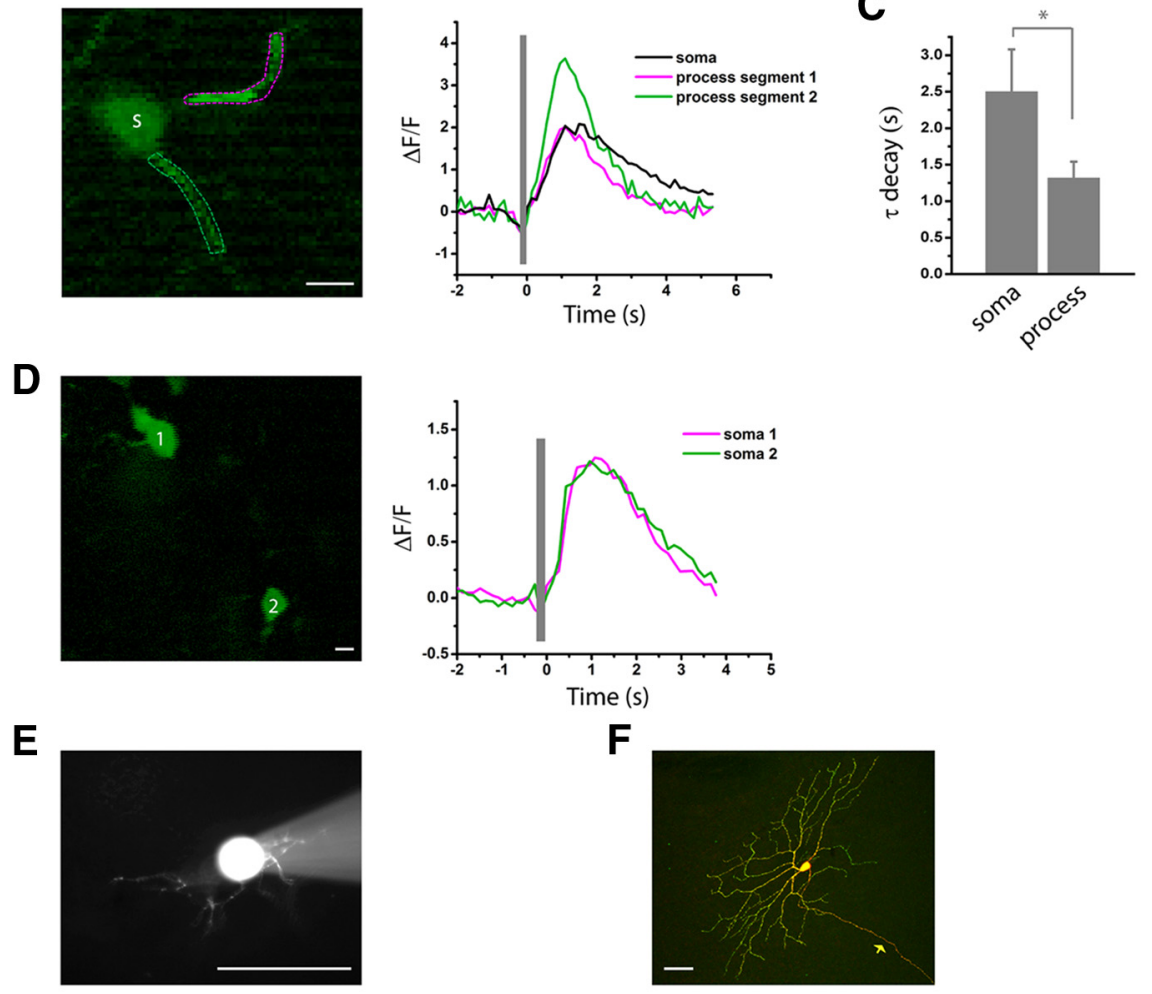

$\mathbf{F}$
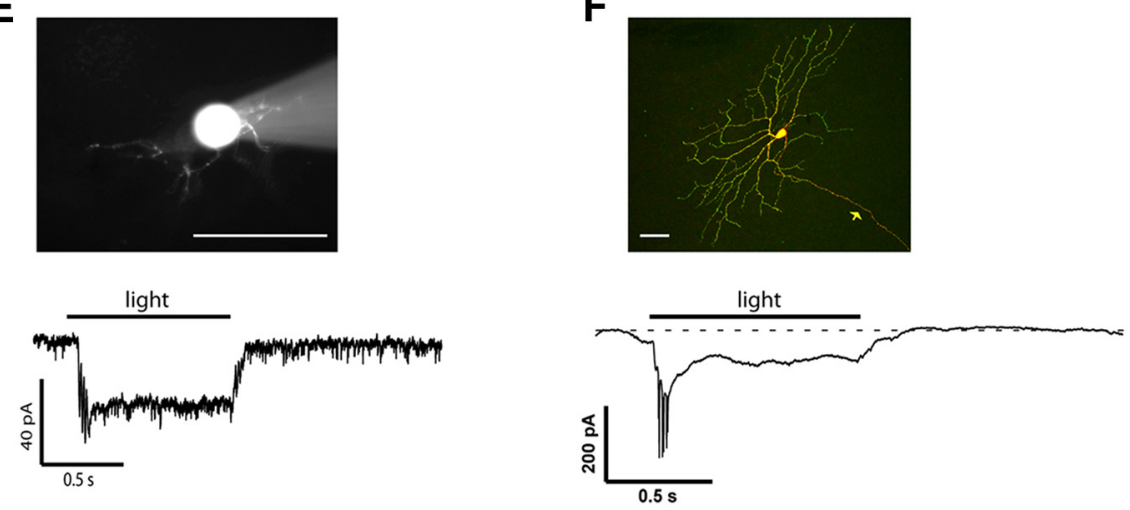

Figure 12. $r A A V / E n v A$ rabies virus-mediated expression of GCaMP3 and ChR2 permits cell type-specific functional imaging and optogenetic manipulation in the retina. GCaMP3 or ChR2-venus was delivered to the retina by intravitreal injection of rAAV2(YF4)-CBA-DIO-TVA followed by either EnvA-SAD $\triangle$ G-GCaMP3 or EnvA-SADAG-ChR2-venus. A-D, Lightevoked GCaMP3 responses recorded from Cre-expressing amacrine and ganglion cells. The visual stimulus was a brief light flash (timing shown by the gray bar). The fluorescence responses of the calcium indicator were imaged with a two-photon microscope. $\boldsymbol{A}$, Light-evoked GCaMP3 responses recorded from the somas $(S)$ and proximal processes of two CRH-2 amacrine cells. Regions of interest are marked by colored dashed lines, with corresponding traces presented in the same color. $\boldsymbol{B}, \boldsymbol{C}$, Comparison of rise $(\boldsymbol{B})$ and decay $(\boldsymbol{C})$ kinetics of GCaMP3 responses recorded from the soma and proximal processes of three $\mathrm{CRH}-2$ amacrine cells including the two cells shown in $\boldsymbol{A}$. Time to peak is measured from the end of light flash to the peak of fluorescence response. Decay time constant is calculated from a single exponential fit to each response. Data are presented as mean $\pm \operatorname{SEM}\left(n=3\right.$ for soma and $n=8$ for process), ${ }^{*} p<0.05$. D, Light-evoked GCaMP3 responses recorded from the somas of two CCK-RGCS. E, F, ChR2 enables light-controlled activation of Cre-expressing amacrine and ganglion cells. $\boldsymbol{E}$, Sustained inward current recorded from a ChR2-positive CRH-1 amacrine cell (shown with sulforhodamine 101 fill during whole-cell recording) in response to a $470 \pm 20 \mathrm{~nm}$ light stimulus (duration indicated by the horizontal bar). $\boldsymbol{F}$, Current spikes followed by a sustained inward current recorded in a ChR2-positive CRH-RGC in response to the stimulus. The cell is shown with antibody staining after whole-cell recording and fixation. Green, ChR2-venus; red, Neurobiotin fill; arrow, RGC axon. For both $\boldsymbol{E}$ and $\boldsymbol{F}$, the stimulus intensity was $3.05 \mathrm{~W}-\mathrm{cm}^{-2}$. The currents were recorded in voltage clamp at a holding potential of $-70 \mathrm{mV}$. The holding current in $\boldsymbol{E}$ was $-31.5 \mathrm{pA}$ and in $\boldsymbol{F}$ was $-6.2 \mathrm{pA}$. Traces are averages of 3 or more responses. Scale bars: $\boldsymbol{A}, \boldsymbol{D}, 10 \mu \mathrm{m} ; \boldsymbol{E}, \boldsymbol{F}, 50 \mu \mathrm{m}(n=8$ cells from 3 mice for $\boldsymbol{E}$ and $\boldsymbol{F})$. strain that expressed GFP in a variety of retinal cells. Together, these studies revealed that amacrine cells are the most diverse class of neurons in the retina, comprising as many distinct types as in the rest of the retina combined. This heterogeneity has impeded the study of function because, except for a few types (e.g., the AII, A17, dopaminergic, and starburst amacrine cells), it has been difficult to repeatedly recognize and target cells for recording based on morphological criteria. The need for cell type-specific markers is especially acute for wide-field amacrine cells, which have broad ramifications, low abundance, and deeply buried cell bodies that are poorly accessible to whole-cell recording.

To date, only a handful of Cre driver lines targeting amacrine cells have been reported, including a ChAT-cre/Jax line with labeled SACs (Ivanova et al., 2010), a Neurod6-Cre line with labeled nGnG (neither glycinergic nor GABAergic) amacrine cells (Kay et al., 2011a), and a VGLUT3-cre line with labeled VGLUT3+ amacrine cells (Grimes et al., 2011). We characterized the amacrine cell expression patterns in nine newly developed Cre lines (Taniguchi et al., 2011) that used promoters for neuropeptides, transcription factors, and transmitter pathway enzymes that are commonly found in GABAergic interneurons. We identified two new types of amacrine cells, a medium-field CRH-1 and a wide-field SST-1, and several wide-field amacrine cells that have been described but not systematically studied due to a lack of genetic markers: CRH-2 (nNOS-1), VIP-1, and nNOS-2. We showed that the CRH-1 is an asymmetric medium-field amacrine cell that is monostratified near the GCL border (Yeh and Olschowka, 1989). Medium-field amacrine cells typically have diffuse dendrites spanning several strata in the IPL and thus probably participate in "vertical integration" (MacNeil and Masland, 1998; Roska and Werblin, 2001). The horizontally spanning morphology of the CRH-1 amacrine cells suggests that it might perform a different computation versus other medium-field amacrine cells. In contrast to medium-field cells, widefield amacrine cells are hypothesized to modulate retinal processing in a global fashion. Wide-field amacrine cells can be divided into two groups, axonless and axon-bearing (or polyaxonal). Here, we identified two axonless wide-field amacrine cells: VIP-1 and nNOS-2. The other two amacrine cell types, $\mathrm{CRH}-2$ (nNOS-1) and SST-1, have long-range 
axon-like processes that covered a large portion of the retina. In agreement with previous studies, the level of stratification is a major parameter for distinguishing between the different types of wide-field amacrine cells (Badea and Nathans, 2004; Lin and Masland, 2006). CRH-2 (nNOS-1) amacrine cells send a majority of their dendritic arbors to SL1-SL2 while maintaining their axons in SL9-SL10. SST-1 amacrine cells have exactly the opposite arrangement. It has been reported that, in axon-bearing widefield amacrine cells, the dendrites receive input from bipolar cells and the axons propagate action potentials from the soma to the periphery (Cook and Werblin, 1994; Völgyi et al., 2001; Davenport et al., 2007). Thus, these cells might be functionally polarized like conventional neurons.

Ganglion cells (RGCs) are a much better understood class compared with amacrine cells, but are difficult to individually target because of a paucity of distinctive molecular markers. Approximately 20 subtypes of RGCs have been morphologically identified, but fewer than half have well described local circuits and central projections. Although several Cre drivers targeting specific types of RGCs have been described (Münch et al., 2009; Ivanova et al., 2010, 2013; Kim et al., 2010; Farrow et al., 2013), at least half of the RGC types lack specific drivers. In this study, we identified five RGC subtypes in the CRH-Cre driver and CCK-Cre driver lines. Since our approach includes a virus used for monosynaptic tracing (Wickersham et al., 2007a,b), retrograde tracing of the presynaptic partners of ganglion cells is enabled. Similarly, the ability to reliably and reproducibly identify the postsynaptic relay neurons of RGCs can be enhanced by genetic access to specific cell types.

\section{Conclusion}

Current genetic approaches use specific promoters with the goal of targeting expression to a single cell type. However, most lines show Cre expression in multiple cell types, precluding a simple analysis of single-cell morphology and stratification. We show that individual cells and types can be resolved by concatenating virus treatments. Viruses such as the rabies used in this study can be engineered to selectively transduce cell types by modifying recognition properties of the virus coat and cell membrane. The selectivity can be further enhanced by using specific promoters to control transgene expression. In addition, when the targeted cell types have unique axonal projections, viral infection can be initiated from their axonal terminals as demonstrated by our retrograde labeling of RGCs in the CCK-ires-Cre driver line. This approach has proved to be especially efficient in separating RGCs from other retinal cell types. Other viruses, such as vesicular stomatitis virus, lentivirus, and herpes virus, have been modified for use in pathway tracing (Mazarakis et al., 2001; Lima et al., 2009; Beier et al., 2011; Kato et al., 2011). In the near future, applying a sequence of viruses with different specificities may offer the possibility of targeting different labels to specific neuron types or individual neurons.

\section{References}

Badea TC, Nathans J (2004) Quantitative analysis of neuronal morphologies in the mouse retina visualized by using a genetically directed reporter. J Comp Neurol 480:331-351. CrossRef Medline

Beier KT, Saunders A, Oldenburg IA, Miyamichi K, Akhtar N, Luo L, Whelan SP, Sabatini B, Cepko CL (2011) Anterograde or retrograde transsynaptic labeling of CNS neurons with vesicular stomatitis virus vectors. Proc Natl Acad Sci U S A 108:15414-15419. CrossRef Medline

Borghuis BG, Tian L, Xu Y, Nikonov SS, Vardi N, Zemelman BV, Looger LL
(2011) Imaging light responses of targeted neuron populations in the rodent retina. J Neurosci 31:2855-2867. CrossRef Medline

Boyden ES, Zhang F, Bamberg E, Nagel G, Deisseroth K (2005) Millisecondtimescale, genetically targeted optical control of neural activity. Nat Neurosci 8:1263-1268. CrossRef Medline

Buffelli M, Burgess RW, Feng G, Lobe CG, Lichtman JW, Sanes JR (2003) Genetic evidence that relative synaptic efficacy biases the outcome of synaptic competition. Nature 424:430-434. CrossRef Medline

Cook PB, Werblin FS (1994) Spike initiation and propagation in wide field transient amacrine cells of the salamander retina. J Neurosci 14:38523861. Medline

Coombs J, van der List D, Wang GY, Chalupa LM (2006) Morphological properties of mouse retinal ganglion cells. Neuroscience 140:123-136. CrossRef Medline

Dalkara D, Byrne LC, Klimczak RR, Visel M, Yin L, Merigan WH, Flannery JG, Schaffer DV (2013) In vivo-directed evolution of a new adenoassociated virus for therapeutic outer retinal gene delivery from the vitreous. Sci Transl Med 5:189ra176. CrossRef Medline

Davenport CM, Detwiler PB, Dacey DM (2007) Functional polarity of dendrites and axons of primate A1 amacrine cells. Vis Neurosci 24:449-457. CrossRef Medline

Deyle DR, Russell DW (2009) Adeno-associated virus vector integration. Curr Opin Mol Ther 11:442-447. Medline

Diamond JS, Lukasiewicz PD (2012) Amacrine cells: seeing the forest and the trees. Vis Neurosci 29:1-2. CrossRef Medline

Famiglietti EV (1992) Polyaxonal amacrine cells of rabbit retina: morphology and stratification of PA1 cells. J Comp Neurol 316:391-405. CrossRef Medline

Farrow K, Teixeira M, Szikra T, Viney TJ, Balint K, Yonehara K, Roska B (2013) Ambient illumination toggles a neuronal circuit switch in the retina and visual perception at cone threshold. Neuron 78:325-338. CrossRef Medline

Grimes WN, Seal RP, Oesch N, Edwards RH, Diamond JS (2011) Genetic targeting and physiological features of VGLUT3+ amacrine cells. Vis Neurosci 28:381-392. CrossRef Medline

Hayes BP (1984) Cell populations of the ganglion cell layer: displaced amacrine and matching amacrine cells in the pigeon retina. Exp Brain Res 56:565-573. Medline

Hofbauer A, Dräger UC (1985) Depth segregation of retinal ganglion cells projecting to mouse superior colliculus. J Comp Neurol 234:465-474. CrossRef Medline

Huang ZJ, Zeng H (2013) Genetic approaches to neural circuits in the mouse. Annu Rev Neurosci 36:183-215. CrossRef Medline

Huberman AD, Manu M, Koch SM, Susman MW, Lutz AB, Ullian EM, Baccus SA, Barres BA (2008) Architecture and activity-mediated refinement of axonal projections from a mosaic of genetically identified retinal ganglion cells. Neuron 59:425-438. CrossRef Medline

Ivanova E, Hwang GS, Pan ZH (2010) Characterization of transgenic mouse lines expressing Cre recombinase in the retina. Neuroscience 165:233243. CrossRef Medline

Ivanova E, Lee P, Pan ZH (2013) Characterization of multiple bistratified retinal ganglion cells in a Purkinje cell protein 2-Cre transgenic mouse line. J Comp Neurol 521:2165-2180. CrossRef Medline

Kato S, Kobayashi K, Inoue K, Kuramochi M, Okada T, Yaginuma H, Morimoto K, Shimada T, Takada M (2011) A lentiviral strategy for highly efficient retrograde gene transfer by pseudotyping with fusion envelope glycoprotein. Hum Gene Ther 22:197-206. CrossRef Medline

Kay JN, Voinescu PE, Chu MW, Sanes JR (2011a) Neurod6 expression defines new retinal amacrine cell subtypes and regulates their fate. Nat Neurosci 14:965-972. CrossRef Medline

Kay JN, De la Huerta I, Kim IJ, Zhang Y, Yamagata M, Chu MW, Meister M, Sanes JR (2011b) Retinal ganglion cells with distinct directional preferences differ in molecular identity, structure, and central projections. J Neurosci 31:7753-7762. CrossRef Medline

Kim IJ, Zhang Y, Yamagata M, Meister M, Sanes JR (2008) Molecular identification of a retinal cell type that responds to upward motion. Nature 452:478-482. CrossRef Medline

Kim IJ, Zhang Y, Meister M, Sanes JR (2010) Laminar restriction of retinal ganglion cell dendrites and axons: subtype-specific developmental patterns revealed with transgenic markers. J Neurosci 30:1452-1462. CrossRef Medline

Kolb H, Nelson R, Mariani A (1981) Amacrine cells, bipolar cells and gan- 
glion cells of the cat retina: a Golgi study. Vis Res 21:1081-1114. CrossRef Medline

Kong JH, Fish DR, Rockhill RL, Masland RH (2005) Diversity of ganglion cells in the mouse retina: unsupervised morphological classification and its limits. J Comp Neurol 489:293-310. CrossRef Medline

Lima SQ, Hromádka T, Znamenskiy P, Zador AM (2009) PINP: a new method of tagging neuronal populations for identification during in vivo electrophysiological recording. PLoS One 4:e6099. CrossRef Medline

Lin B, Masland RH (2006) Populations of wide-field amacrine cells in the mouse retina. J Comp Neurol 499:797-809. CrossRef Medline

MacNeil MA, Masland RH (1998) Extreme diversity among amacrine cells: implications for function. Neuron 20:971-982. CrossRef Medline

MacNeil MA, Heussy JK, Dacheux RF, Raviola E, Masland RH (1999) The shapes and numbers of amacrine cells: matching of photofilled with Golgi-stained cells in the rabbit retina and comparison with other mammalian species. J Comp Neurol 413:305-326. CrossRef Medline

Madisen L, Zwingman TA, Sunkin SM, Oh SW, Zariwala HA, Gu H, Ng LL, Palmiter RD, Hawrylycz MJ, Jones AR, Lein ES, Zeng H (2010) A robust and high-throughput Cre reporting and characterization system for the whole mouse brain. Nat Neurosci 13:133-140. CrossRef Medline

Mazarakis ND, Azzouz M, Rohll JB, Ellard FM, Wilkes FJ, Olsen AL, Carter EE, Barber RD, Baban DF, Kingsman SM, Kingsman AJ, O’Malley K, Mitrophanous KA (2001) Rabies virus glycoprotein pseudotyping of lentiviral vectors enables retrograde axonal transport and access to the nervous system after peripheral delivery. Hum Mol Genet 10:2109-2121. CrossRef Medline

Münch TA, da Silveira RA, Siegert S, Viney TJ, Awatramani GB, Roska B (2009) Approach sensitivity in the retina processed by a multifunctional neural circuit. Nat Neurosci 12:1308-1316. CrossRef Medline

Osakada F, Mori T, Cetin AH, Marshel JH, Virgen B, Callaway EM (2011) New rabies virus variants for monitoring and manipulating activity and gene expression in defined neural circuits. Neuron 71:617-631. CrossRef Medline

Pang JJ, Gao F, Wu SM (2003) Light-evoked excitatory and inhibitory synaptic inputs to ON and OFF alpha ganglion cells in the mouse retina. J Neurosci 23:6063-6073. Medline

Perry VH (1981) Evidence for an amacrine cell system in the ganglion cell layer of the rat retina. Neuroscience 6:931-944. CrossRef Medline

Perry VH, Morris RJ, Raisman G (1984) Is Thy-1 expressed only by ganglion cells and their axons in the retina and optic nerve? J Neurocytol 13:809824. CrossRef Medline

Petreanu L, Mao T, Sternson SM, Svoboda K (2009) The subcellular organization of neocortical excitatory connections. Nature 457:1142-1145. CrossRef Medline

Petrs-Silva H, Dinculescu A, Li Q, Deng WT, Pang JJ, Min SH, Chiodo V, Neeley AW, Govindasamy L, Bennett A, Agbandje-McKenna M, Zhong L, Li B, Jayandharan GR, Srivastava A, Lewin AS, Hauswirth WW (2011) Novel properties of tyrosine-mutant AAV2 vectors in the mouse retina. Mol Ther 19:293-301. CrossRef Medline

Roska B, Werblin F (2001) Vertical interactions across ten parallel, stacked representations in the mammalian retina. Nature 410:583-587. CrossRef Medline

Saszik S, DeVries SH (2012) A mammalian retinal bipolar cell uses both graded changes in membrane voltage and all-or-nothing $\mathrm{Na}+$ spikes to encode light. J Neurosci 32:297-307. CrossRef Medline

Siegert S, Scherf BG, Del Punta K, Didkovsky N, Heintz N, Roska B (2009) Genetic address book for retinal cell types. Nat Neurosci 12:1197-1204. CrossRef Medline

Stafford DK, Dacey DM (1997) Physiology of the Al amacrine: a spiking, axon-bearing interneuron of the macaque monkey retina. Vis Neurosci 14:507-522. CrossRef Medline

Sun W, Li N, HeS (2002) Large-scale morphological survey of mouse retinal ganglion cells. J Comp Neurol 451:115-126. CrossRef Medline

Taniguchi H, He M, Wu P, Kim S, Paik R, Sugino K, Kvitsani D, Fu Y, Lu J, Lin Y, Miyoshi G, Shima Y, Fishell G, Nelson SB, Huang ZJ (2011) A resource of Cre driver lines for genetic targeting of GABAergic neurons in cerebral cortex. Neuron 71:995-1013. CrossRef Medline

Tian L, Hires SA, Mao T, Huber D, Chiappe ME, Chalasani SH, Petreanu L, Akerboom J, McKinney SA, Schreiter ER, Bargmann CI, Jayaraman V, Svoboda K, Looger LL (2009) Imaging neural activity in worms, flies and mice with improved GCaMP calcium indicators. Nat Methods 6:875881. CrossRef Medline

Trenholm S, Johnson K, Li X, Smith RG, Awatramani GB (2011) Parallel mechanisms encode direction in the retina. Neuron 71:683-694. CrossRef Medline

Völgyi B, Xin D, Amarillo Y, Bloomfield SA (2001) Morphology and physiology of the polyaxonal amacrine cells in the rabbit retina. J Comp Neurol 440:109-125. CrossRef Medline

Völgyi B, Chheda S, Bloomfield SA (2009) Tracer coupling patterns of the ganglion cell subtypes in the mouse retina. J Comp Neurol 512:664-687. CrossRef Medline

Wickersham IR, Finke S, Conzelmann KK, Callaway EM (2007a) Retrograde neuronal tracing with a deletion-mutant rabies virus. Nat Methods 4:47-49. CrossRef Medline

Wickersham IR, Lyon DC, Barnard RJ, Mori T, Finke S, Conzelmann KK, Young JA, Callaway EM (2007b) Monosynaptic restriction of transsynaptic tracing from single, genetically targeted neurons. Neuron 53:639647. CrossRef Medline

Yeh HH, Olschowka JA (1989) A system of corticotropin releasing factorcontaining amacrine cells in the rat retina. Neuroscience 33:229-240. CrossRef Medline

Yonehara K, Farrow K, Ghanem A, Hillier D, Balint K, Teixeira M, Jüttner J, Noda M, Neve RL, Conzelmann KK, Roska B (2013) The first stage of cardinal direction selectivity is localized to the dendrites of retinal ganglion cells. Neuron 79:1078-1085. CrossRef Medline

Zhong L, Li B, Mah CS, Govindasamy L, Agbandje-McKenna M, Cooper M, Herzog RW, Zolotukhin I, Warrington KH Jr, Weigel-Van Aken KA, Hobbs JA, Zolotukhin S, Muzyczka N, Srivastava A (2008) Next generation of adeno-associated virus 2 vectors: point mutations in tyrosines lead to high-efficiency transduction at lower doses. Proc Natl Acad Sci U S A 105:7827-7832. CrossRef Medline 